\title{
Autoimmune polyendocrine syndrome type 1: an Italian survey on 158 patients
}

\author{
S. Garelli ${ }^{1,2} \cdot$ M. Dalla Costa ${ }^{1,3} \cdot$ C. Sabbadin ${ }^{1} \cdot$ S. Barollo ${ }^{1} \cdot$ B. Rubin ${ }^{1} \cdot$ R. Scarpa ${ }^{1} \cdot$ S. Masiero ${ }^{1} \cdot$ A. Fierabracci ${ }^{4}$.

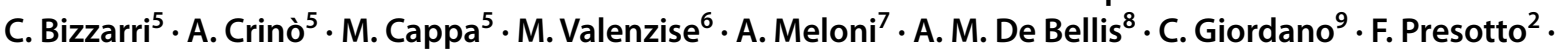 \\ R. Perniola ${ }^{10}$ - D. Capalbo ${ }^{11}$ - M. C. Salerno ${ }^{12}$ - A. Stigliano ${ }^{13} \cdot$ G. Radetti ${ }^{14} \cdot$ V. Camozzi ${ }^{1}$ - N. A. Greggio ${ }^{15} \cdot$ F. Bogazzi $^{16}$. \\ I. Chiodini ${ }^{17}$. U. Pagotto ${ }^{18}$. S. K. Black ${ }^{19}$. S. Chen ${ }^{19}$. B. Rees Smith ${ }^{19}$. J. Furmaniak ${ }^{19} \cdot$ G. Weber ${ }^{20} \cdot$ F. Pigliaru ${ }^{21}$. \\ L. De Sanctis ${ }^{22} \cdot$ C. Scaroni ${ }^{1} \cdot$ C. Betterle ${ }^{1}$
}

Received: 8 March 2021 / Accepted: 29 April 2021 / Published online: 18 May 2021

(c) The Author(s) 2021

\begin{abstract}
Background Autoimmune Polyglandular Syndrome type 1 (APS-1) is a rare recessive inherited disease, caused by AutoImmune Regulator (AIRE) gene mutations and characterized by three major manifestations: chronic mucocutaneous candidiasis (CMC), chronic hypoparathyroidism (CH) and Addison's disease (AD).

Methods Autoimmune conditions and associated autoantibodies (Abs) were analyzed in 158 Italian patients (103 females and 55 males; F/M 1.9/1) at the onset and during a follow-up of $23.7 \pm 15.1$ years. AIRE mutations were determined.

Results The prevalence of APS-1 was 2.6 cases/million (range $0.5-17$ in different regions). At the onset $93 \%$ of patients presented with one or more components of the classical triad and 7\% with other components. At the end of follow-up, $86.1 \%$ had $\mathrm{CH}, 77.2 \% \mathrm{AD}, 74.7 \% \mathrm{CMC}, 49.5 \%$ premature menopause, $29.7 \%$ autoimmune intestinal dysfunction, $27.8 \%$ autoimmune thyroid diseases, $25.9 \%$ autoimmune gastritis/pernicious anemia, $25.3 \%$ ectodermal dystrophy, $24 \%$ alopecia, $21.5 \%$ autoimmune hepatitis, $17 \%$ vitiligo, $13.3 \%$ cholelithiasis, $5.7 \%$ connective diseases, $4.4 \%$ asplenia, $2.5 \%$ celiac disease and 13.9\% cancer. Overall, 991 diseases (6.3 diseases/patient) were found. Interferon- $\omega$ Abs (IFN $\omega$ Abs) were positive in $91.1 \%$ of patients. Overall mortality was $14.6 \%$. The AIRE mutation R139X was found in $21.3 \%$ of tested alleles, R257X in $11.8 \%$, W78R in $11.4 \%, \mathrm{C} 322 \mathrm{fsX} 372$ in $8.8 \%, \mathrm{~T} 16 \mathrm{M}$ in $6.2 \%, \mathrm{R} 203 \mathrm{X}$ in $4 \%$, and $\mathrm{A} 21 \mathrm{~V}$ in $2.9 \%$. Less frequent mutations were present in $12.9 \%$, very rare in $9.6 \%$ while no mutations in $11 \%$ of the cases.

Conclusions In Italy, APS-1 is a rare disorder presenting with the three major manifestations and associated with different AIRE gene mutations. IFN $\omega$ Abs are markers of APS-1 and other organ-specific autoantibodies are markers of clinical, subclinical or potential autoimmune conditions.
\end{abstract}

Keywords Autoimmune-poly-endocrine-candidiasis-ectodermal-dystrophy (APECED) · Autoimmune Polyglandular Syndrome type 1 (APS-1) · AIRE gene mutations · Chronic mucocutaneous candidiasis · Chronic hypoparathyroidism · Addison's disease $\cdot$ Interferon autoantibodies

\section{Abbreviations}

$17 \alpha$ OHAbs $\quad 17 \alpha$-Hydroxylase autoantibodies

21-OHAbs 21-Hydroxylase autoantibodies

$\mathrm{AD}$

ACA

AITD

Addison's disease

Adrenal cortex autoantibodies

Autoimmune thyroid diseases

S. Garelli and M. Dalla Costa contributed equally to this work.

C. Betterle

corrado.betterle@unipd.it

Extended author information available on the last page of the article
AG Autoimmune gastritis

AIH Autoimmune hepatitis

AIRE Autoimmune regulator

AIREp Autoimmune regulator protein

ACD Autoimmune connective diseases

AADCAbs Aromatic-L-aminoacid decarboxylase autoantibodies

AIH Autoimmune hepatitis

AID Autoimmune intestinal dysfunction

APECED Autoimmune poly-endocrine-candidiasisectodermal-dystrophy 


\begin{tabular}{|c|c|}
\hline APS-1 & $\begin{array}{l}\text { Autoimmune polyendocrine syndrome type } \\
1\end{array}$ \\
\hline $\mathrm{CD}$ & Celiac disease \\
\hline $\mathrm{CMC}$ & Chronic mucocutaneous candidiasis \\
\hline $\mathrm{CH}$ & Chronic hypoparathyroidism \\
\hline CT & Chronic thyroiditis \\
\hline DM-1 & Diabetes mellitus type 1 \\
\hline ECE-2Abs & $\begin{array}{l}\text { Endothelin-converting enzyme- } 2 \\
\text { autoantibodies }\end{array}$ \\
\hline GADAbs & $\begin{array}{l}\text { Glutamic acid decarboxylase } \\
\text { autoantibodies }\end{array}$ \\
\hline GD & Graves' disease \\
\hline GH & Growth hormone \\
\hline HDAbs & Histidine decarboxylase autoantibodies \\
\hline $\mathrm{HH}$ & Hypergonadotropic hypogonadism \\
\hline IFN $\omega \mathrm{Abs}$ & Interferon- $\omega$ autoantibodies \\
\hline IFA & Intrinsic factor autoantibodies \\
\hline ICA & Islet cell autoantibodies \\
\hline LGLL & Large granular lymphocyte leukemia \\
\hline LKMAbs & Liver-kidney microsomal autoantibodies \\
\hline MPCAbs & Melanin-producing cell autoantibodies \\
\hline MAS-1 & Multiple autoimmune syndrome type 1 \\
\hline NALP-5Abs & $\begin{array}{l}\text { NACHT leucine-rich protein-5 } \\
\text { autoantibodies }\end{array}$ \\
\hline PCA & Parietal cell autoantibodies \\
\hline PA & Pernicious anemia \\
\hline KCNRGAbs & $\begin{array}{l}\text { Potassium channel-regulating } \\
\text { autoantibodies }\end{array}$ \\
\hline POF & Premature ovarian failure \\
\hline PGE & Promiscuous gene expression \\
\hline $\mathrm{IA}_{2} \mathrm{Abs}$ & Second islet antigen autoantibodies \\
\hline SCCAbs & Side-chain cleavage autoantibodies \\
\hline SMA & Smooth muscle autoantibodies \\
\hline SA & Spleen atrophy \\
\hline SEA & Steroid enzyme autoantibodies \\
\hline StCA & Steroid-producing cell autoantibodies \\
\hline $\operatorname{TgAbs}$ & Thyroglobulin autoantibodies \\
\hline TMAbs & Thyroid microsomal autoantibodies \\
\hline TPOAbs & Thyro-peroxidase autoantibodies \\
\hline tTgAbs-IgA & $\begin{array}{l}\text { Tissue transglutaminase autoantibodies of } \\
\text { IgA class }\end{array}$ \\
\hline Tr-4Abs & Transglutaminase- 4 autoantibodies \\
\hline TPHAbs & Tryptophan hydroxylase autoantibodies \\
\hline TSHRAbs & TSH-receptor autoantibodies \\
\hline
\end{tabular}

\section{Introduction}

Autoimmune Polyendocrine Syndrome type 1 (APS-1) (OMIM 240300), also termed Autoimmune Poly-Endocrine-Candidiasis-Ectodermal-Dystrophy (APECED) [1] or multiple autoimmune syndrome type 1 (MAS-1) [2, 3] is a rare disease with a mean prevalence of 10 cases per million inhabitants [4]. The prevalence varies and is higher in patients with consanguinity or in some particular populations [5]. The highest reported prevalence is in the Iranian Jewish population (1 case per 9000 individuals) [6], followed by Finland ( 1 case per 25,000 individuals) [1], Norway (1 case per 90,000 individuals) [7] Poland (1 case per 129,000 individuals) [8], and Ireland (1 case per 130,000 individuals) [9] with the lowest prevalence in France (1 case per 500,000 individuals) [10] and in Japan ( 1 case per 10 million individuals) $[5,11]$. APS-1 is defined by the presence of at least two of the three major diseases: chronic mucocutaneous candidiasis (CMC), chronic hypoparathyroidism $(\mathrm{CH})$ and Addison's disease (AD) [12]. In addition, patients present with other autoimmune and non-autoimmune diseases and ectodermic dystrophy [1, 4, 12-14]. In European cohorts, one or more major manifestations presented at the onset in $80-90 \%$ of patients while a small proportion (5-20\%) presented with other diseases $[5,13,15,16]$. In contrast, in an American cohort, 40-80\% of patients had non-major diseases at manifestation onset and the development of classical manifestations was delayed [17]. These observations have led to establishing new criteria for diagnosing APS-1 which recommend testing for interferon autoantibodies in patients presenting one of the following clinical manifestations: $\mathrm{CMC}, \mathrm{AD}$ (occurring below 20 years of age), $\mathrm{CH}$, premature ovarian failure (occurring below 30 years of age), enamel hypoplasia, periodic fever with rash, non-infectious keratitis or autoimmune hepatitis. If testing for interferon autoantibodies is not available it is recommended to proceed directly with $A I R E$ gene analysis [4]. APS-1 is caused by autosomal recessive mutations of AIRE gene on chromosome 21 (21q22.3). AIRE gene plays an essential role in central tolerance. Mutations in the AIRE gene prevent the elimination of self-reactive $T$ cells at central level and induce a Treg defect at peripheral levels $[4,18,19]$. This leads to the development of multiple autoimmune diseases at a young age [4, 20, 21]. The most frequent mutation is R257X on exon 6 detectable in $87 \%$ of Finnish patients although it was also found in other populations [4, 5, 15, 22, 23]. Mutations C322fsX372 or del13 in exon 8 are typical of AngloSaxon populations but can also occur in patients of different descent [4, 5, 22-24]. To date, more than 126 AIRE mutations have been identified [4, 5, 20]. Although APS-1 is very rare, 20 cohorts were described from 1998 to 2018 [6, 8-11, $15,17,20,24-35]$ and a total of 568 patients from different populations have been assessed to date (Table 1 and Supplementary Figure 1). Several reports of Italian patients with APS-1 were published from 1974 to 2016 [22, 26, 36-53]. However, a complete analysis on all the patients with APS-1 in Italy has not been carried out so far. The aim of this study was to collect data on all the APS-1 patients living in Italy. In collaboration with the Italian Society of Endocrinology (SIE), the Italian Society of Pediatric Endocrinology and 


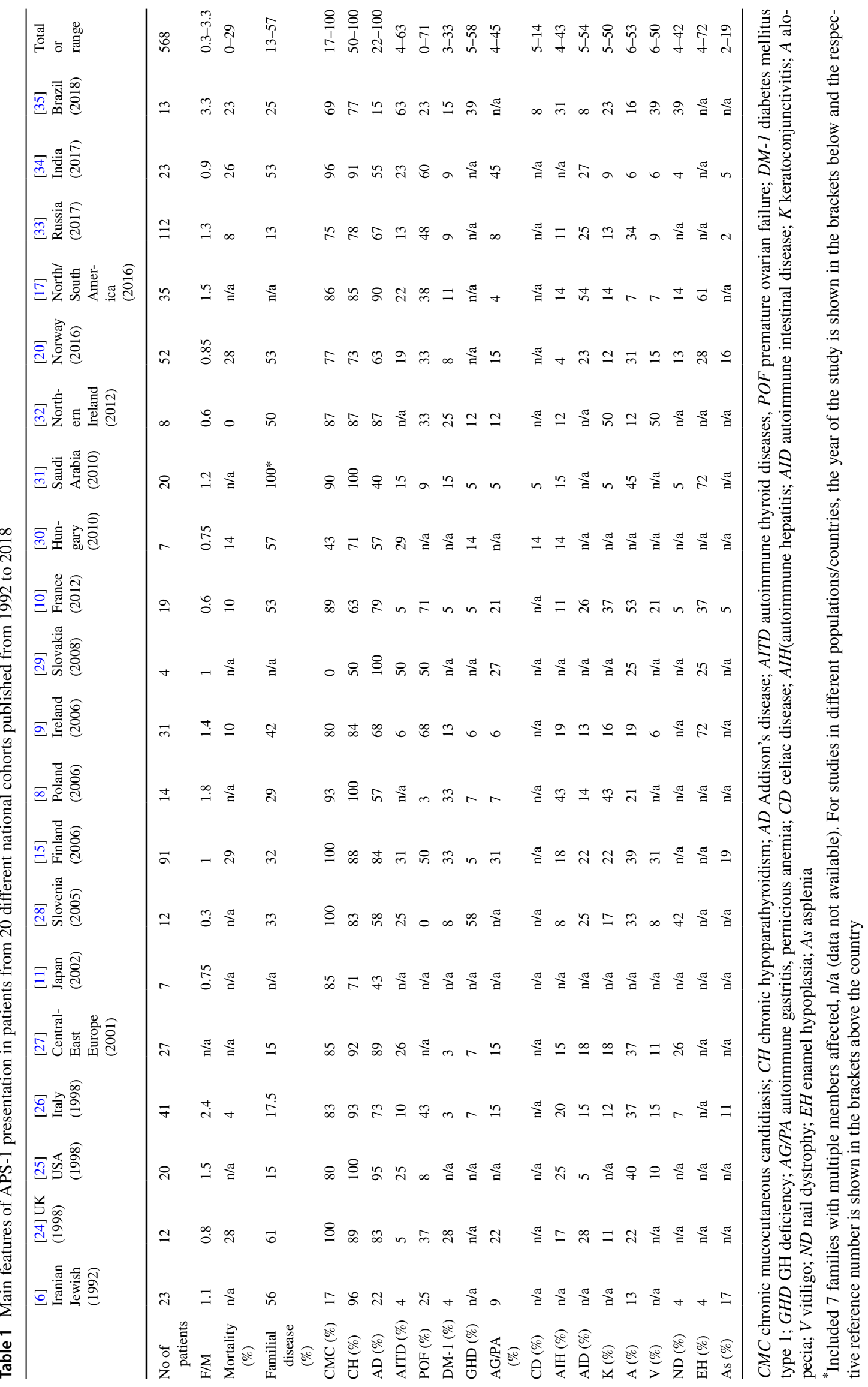


Diabetology (SIEDP), the Association of Medical Endocrinologists (AME) and the Italian Association of Patients with Addison's disease (AIPAd), all the APS-1 patients who were diagnosed and followed up in different specialist endocrine centers in Italy have been recruited, their sera and/or DNA samples were collected and the first Italian national register of patients with APS-1 has been created.

\section{Patients and methods}

\section{Patients}

One hundred and sixty-seven patients with APS-1 were enrolled into the study. Data on age, gender, manifestations, serum biochemistry and serum autoantibody profiles at onset and during a follow-up were collected. The diagnosis of the various diseases was performed according to the criteria previously published $[3,54]$ and summarized in the Table 2. Furthermore, AIRE gene mutations were analyzed. APS-1 was diagnosed using the classical clinical criteria defined in 1980 [12] or according to the new criteria [4]. The ethnic origin and for Italian patients the geographical region of provenance of their families were also recorded. The study was performed according to the principles of the Helsinki declaration. The patients gave their written consent to participate in this study. The study was approved by the ethical committee of the Azienda Ospedaliera-Universitaria in Padua, Italy (Ref. No 1299P and 1583P).

\section{AIRE gene mutation}

All 14 exons of the AIRE gene and their flanking exon-intron boundaries (GenBank accession no. Aj009610) were analyzed in 136 patients and in 170 non affected family members using previously described methods [22]. Data were analyzed for the total Italian cohort and also for groups of patients according to their regional origin.

\section{Autoantibodies}

Patients' sera were screened for interferon- $\omega$ autoantibodies (IFN $\omega \mathrm{Abs}$ ) and for the range of organ and non-organspecific autoantibodies relevant for various autoimmune diseases using methods described previously [26, 41, 55-62]. Autoantibody positivity confirmed the diagnosis in patients who presented with clinical autoimmune diseases. Autoantibody positive patients who did not display clinical signs/ symptoms and/or had no biochemical markers of a subclinical disease were periodically followed up to assess the progression to the disease and to calculate the annual incidence of the disease.

\section{Statistical analysis}

Comparison of female/male ratios, correlations between autoantibodies and the specific diseases, genotype and phenotype, geographic provenance and phenotype were analyzed by Chi-square test. Statistical significance was determined at $p<0.05$. Survival analysis was performed using Kaplan-Meier analysis. Differences between subgroups were tested with Log-Rank and Cox regression.

\section{Results}

\section{Epidemiology}

Between 1965 and 2019, there were 167 patients with APS-1 living in Italy. Of these, 158 were Italians while 9 migrated to Italy from other countries. Out of the 158 Italian APS-1 patients, 103 (65.2\%) were females and 55 males, with a female/male ratio of 1.9/1. Considering the size of the Italian population of 60,589,085 individuals [63], the prevalence of APS- 1 could be estimated at about 2.6 cases/million, corresponding to one case per 384,615 individuals. The prevalence of APS-1 in different Italian regions or macroareas was also estimated [63] and is summarized in Table 3. Furthermore, "hot spot areas" for APS-1 were identified in three Italian regions, for example, 12/28 of cases in Sardinia were found in the "Ogliastra" area, 11/24 of Veneto region cases in "Bassano del Grappa" and 12/15 of Apulia cases in "Salento". The patients were followed up from diagnosis of APS-1 until the date of death or to the end of 2019. The mean follow-up period was $23.7 \pm 15.1$ years (range $1-67$ years). The mean age of the patients at the entry and at the end of the follow-up period was $8.3 \pm 11.8$ years (range $0.5-76)$ and $32 \pm 18$ years (range $3-81$ years), respectively.

\section{APS-1 disease components at the onset and by the end of follow-up}

At the onset of APS-1, 147/158 patients (93\%) showed at least one component of the classical triad, while 11/158 (7\%) presented with other conditions.

\section{Chronic mucocutaneous candidiasis (CMC)}

CMC was present at the onset of APS- 1 in $81 / 158$ patients (51.3\%). In 60/158 (38\%), CMC was isolated, while in $21 / 158(13.3 \%)$, it manifested with other diseases. CMC presented at a mean age of $4.4 \pm 6.4$ years (range $0.5-36$ years). By the end of follow-up, 118/158 patients (74.7\%) were affected by CMC with a mean age at diagnosis of $9.1 \pm$ 13.6 years (range $0.5-79$ years) (Figs. 1, 2). In detail, 12/118 patients $(10.2 \%)$ developed CMC by the age of 1 year, 26 


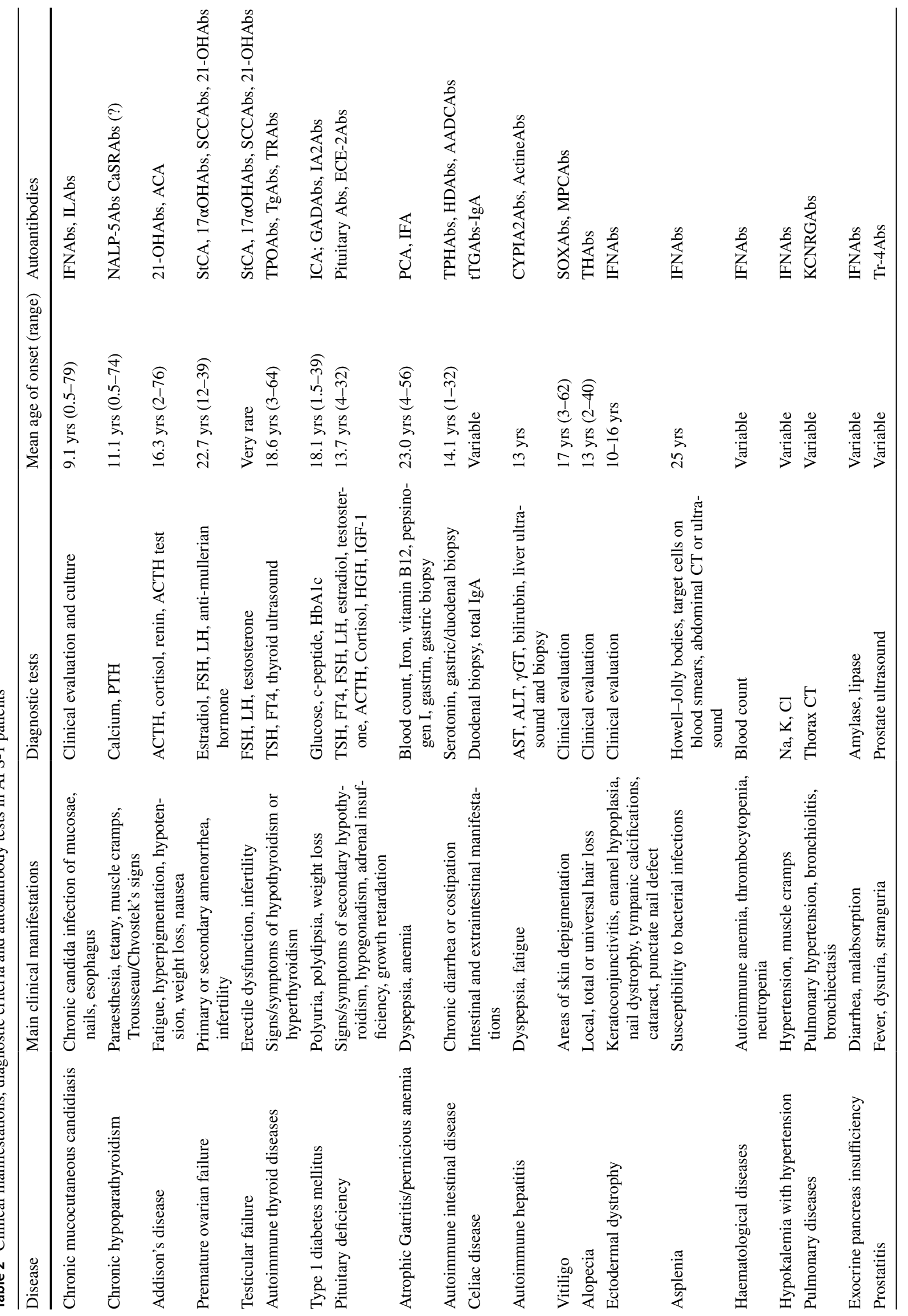


Table 3 Prevalence of APS-1 in the Italian population overall and in different Italian geographic regions or macro-areas

\begin{tabular}{|c|c|c|c|}
\hline Geographical origin of APS- 1 patients & Italian population [62] & $\begin{array}{l}\text { Number of Italian patients } \\
\text { with APS-1 }\end{array}$ & $\begin{array}{l}\text { Prevalence of } \\
\text { patients/million } \\
\text { inhabitants }\end{array}$ \\
\hline Italy (total cases) & $60,589,085$ & 158 & 2.6 \\
\hline Sardinia & $1,653,135$ & 28 & 17.0 \\
\hline North-East Italy & $7,188,201$ & 28 & 3.9 \\
\hline Veneto & $4,907,529$ & 24 & 4.9 \\
\hline Trentino-Alto Adige & $1,062,860$ & 3 & 2.8 \\
\hline Friuli Venezia Giulia & $1,217,872$ & 1 & 0.8 \\
\hline Sicily & $5,056,641$ & 20 & 3.9 \\
\hline Apulia & $4,063,888$ & 15 & 3.7 \\
\hline Campania & $5,839,084$ & 15 & 2.6 \\
\hline South Italy & $2,535,493$ & 8 & 3.2 \\
\hline Calabria & $1,965,128$ & 7 & 3.6 \\
\hline Basilicata & 570,365 & 1 & 1.8 \\
\hline North-West Italy & $15,976,639$ & 14 & 0.9 \\
\hline Lombardy & $10,018,806$ & 6 & 0.6 \\
\hline Piedmont & $4,392,526$ & 7 & 1.6 \\
\hline Liguria & $1,565,307$ & 1 & 0.6 \\
\hline Central Italy & $15,627,457$ & 13 & 0.8 \\
\hline Lazio & $5,898,124$ & 6 & 1.0 \\
\hline Emilia-Romagna & $4,448,841$ & 4 & 0.9 \\
\hline Tuscany & $3,742,437$ & 2 & 0.5 \\
\hline Marche & $1,538,055$ & 1 & 0.6 \\
\hline Patients with parents originating from 2 regions & & 8 & n.d \\
\hline Patients with parents of unspecified regional origin & & 9 & n.d \\
\hline
\end{tabular}

Data on populations were taken from http://www.comuni-italiani.it/regionip.html [62]

n.d. not determined

(22\%) by the age of 2 years, $15(12.7 \%)$ between 2 and 3 years, $22(18.6 \%)$ between 4 and 6 years, $13(11 \%)$ between 7 and 10 years, and 25 (21.2\%) after 10 years of age. For five patients (4.2\%), the age when CMC was diagnosed was not available. The occurrence of CMC in different geographical regions in Italy is summarized in Fig. 3. During follow-up, six patients developed dysphagia and esophageal stenosis requiring periodical endoscopy for pneumatic dilatations.

\section{Chronic hypoparathyroidism (CH)}

$\mathrm{CH}$ was the second most common presentation and the first endocrine disorder at onset of APS-1 in 55/158 (34.8\%) patients. $34 / 158(21.5 \%)$ patients manifested with isolated $\mathrm{CH}$, while in $21 / 158, \mathrm{CH}$ was associated with other diseases (13.3\%). $\mathrm{CH}$ developed at a mean age of $8.4 \pm 10.2$ years (range $0.5-56$ years). By the end of follow-up, $\mathrm{CH}$ was the most frequent disease affecting $136 / 158$ patients $(86.1 \%)$ and presenting at a mean age of $11.1 \pm 12.1$ years (range 0.5-74 years) (Figs. 1, 2). In all, 6/136 patients (4.4\%) developed $\mathrm{CH}$ in the first 2 years of life, 23 (17\%) between 2 and 3 years of age, $41(30.1 \%)$ between 4 and 6 years, $23(16.9 \%)$ between 7 and 10 years, 19 (14\%) between 11 and 20 years, and $20(14.7 \%)$ after 20 years of age. For 4 patients (2.9\%), the age at presentation of $\mathrm{CH}$ was unknown. Figure 3 shows the presentation of $\mathrm{CH}$ in Italian regions. NALP-5Abs were measured in a group of 41 patients with a mean disease duration of 19 years (range $1-30$ years) and $18(44 \%)$ tested positive.

\section{Addison's disease (AD)}

AD developed in 27/158 (17\%) patients at the onset of APS1 , in $10 / 158(6.3 \%)$, it was isolated and in $17 / 158(10.7 \%)$, associated with other diseases. AD developed at a mean age of $18.8 \pm 18.6$ years (range 2-76 years). By the end of the follow-up, 122/158 patients (77.2\%) manifested $\mathrm{AD}$ at a mean age of $16.3 \pm 14.1$ years (range 2-76) (Figs. 1, 2). In 9/121 patients (7.4\%), AD was diagnosed by 3 years of age, in $18(14.9 \%)$ between 4 and 6 years, in $18(14.9 \%)$ between 7 and 8 years, in 17 (14\%) between 9 and 10 years, in 26 (21.5\%) between 11 and 20 years, in 13 (10.7\%) between 21 
Fig. 1 Clinical manifestations at the end of follow-up of APS-1 patients in Italy, presented as a percent of the total number of patients $(n=158)$. $G H$ growth hormone
Fig. 2 Mean age (in years) at the onset of different clinical manifestations in Italian patients with APS-1

05101520253035404550556065707580859095

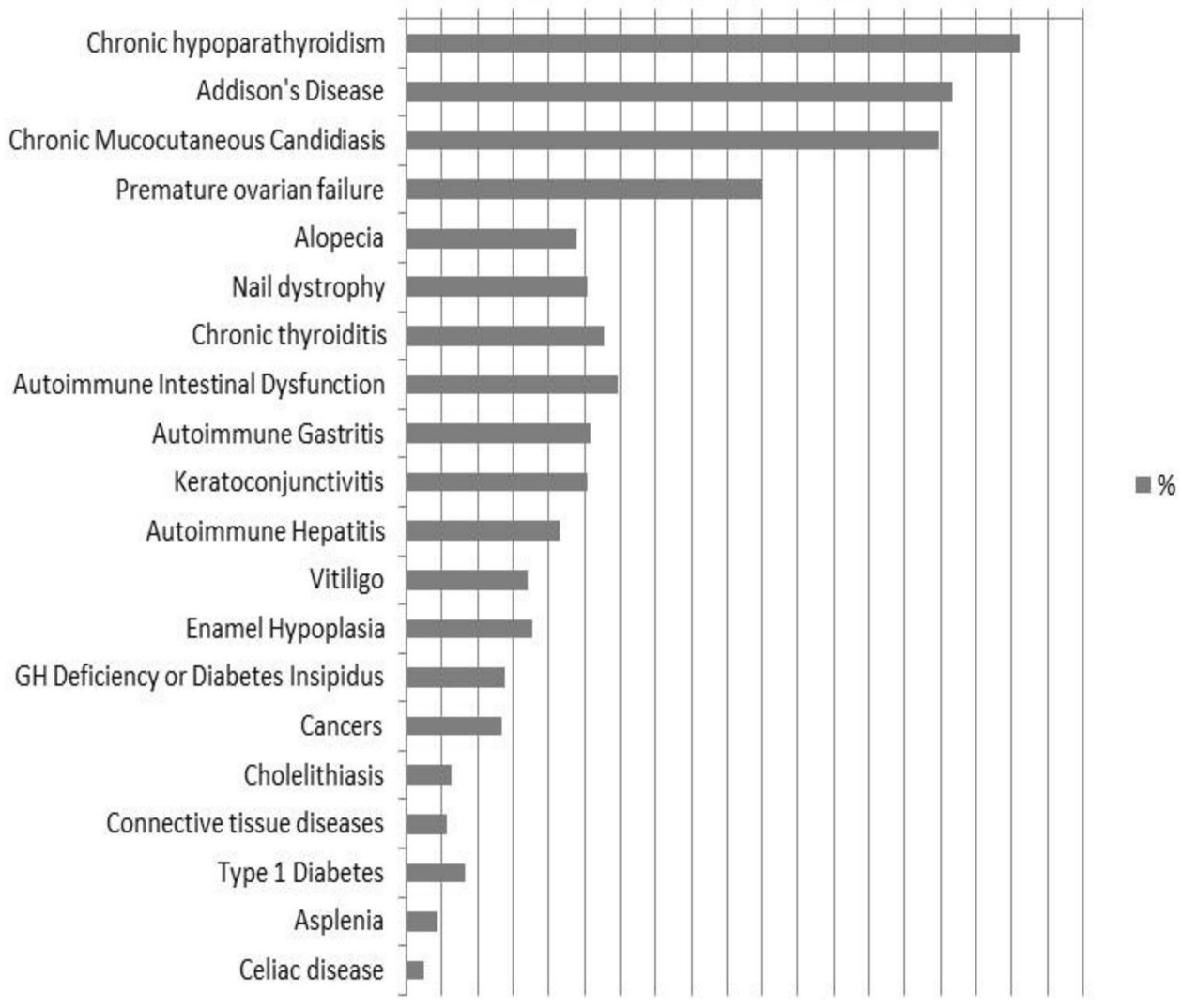

( $\mathrm{GH}=$ growth hormone).

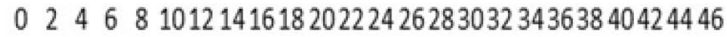

Chronic Mucocutaneous Candidiasis
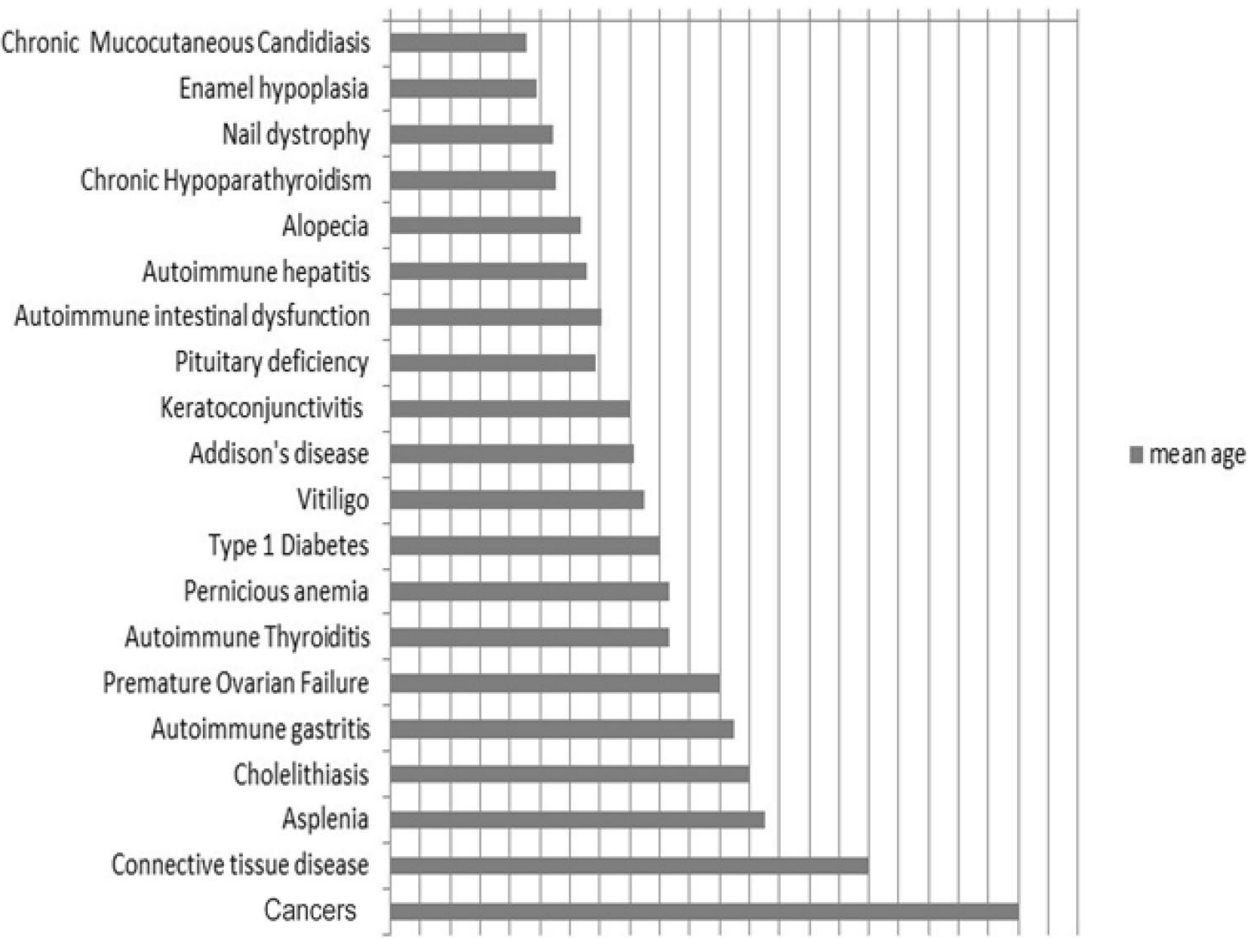


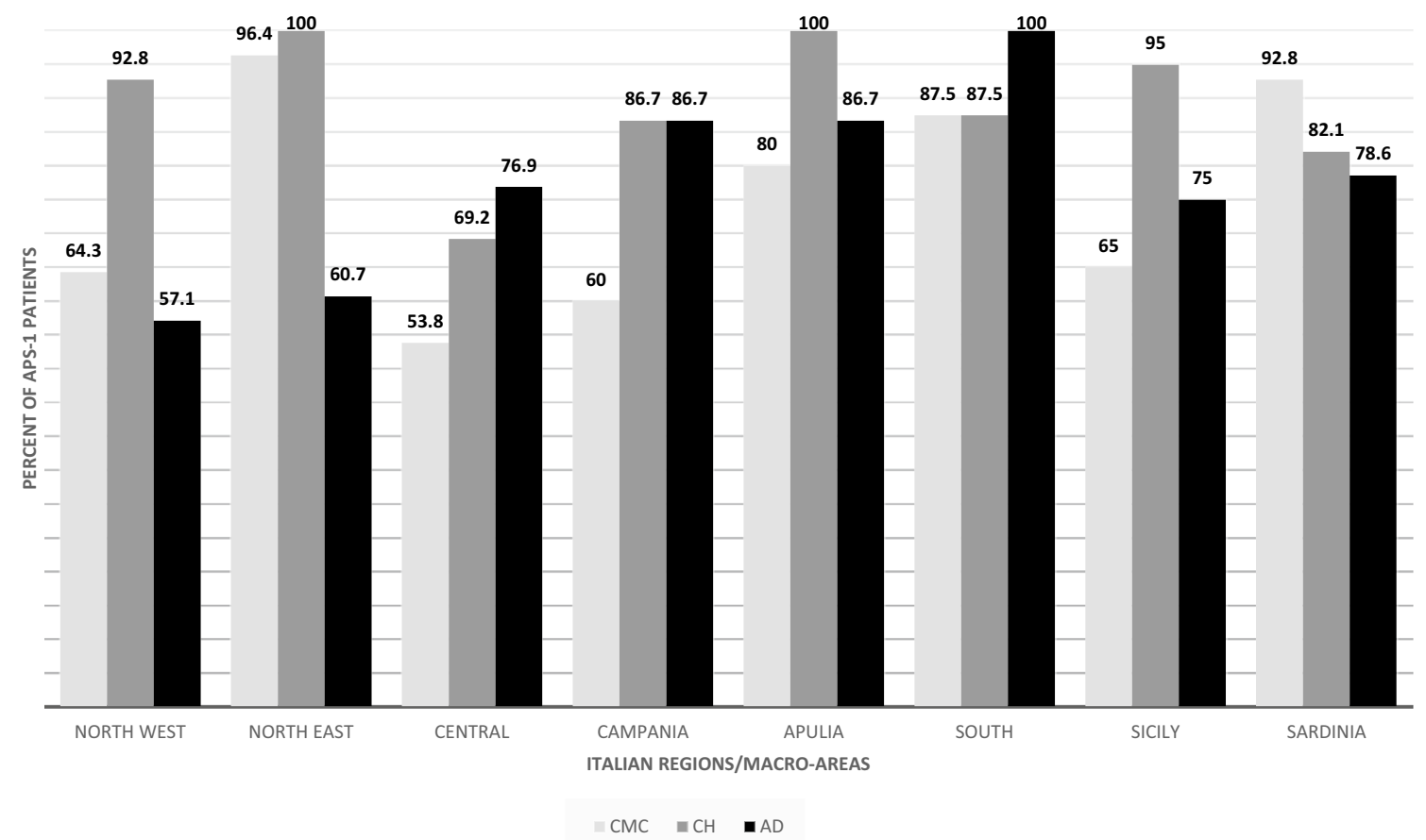

Fig. 3 Occurrence of CMC, $\mathrm{CH}$ and AD in patients with APS-1 from various Italian regions or macro-areas

and 30 years, and in $18(14.9 \%)$ after 30 years. The age at AD onset was not available for three patients. The presentation of AD in APS-1 patients from different Italian regions is summarized in Fig. 3. Adrenal cortex autoantibodies (ACA) were found in 84/104 (80.8\%) and 21-OH autoantibodies (21-OHAbs) in 75/97 patients $(77.3 \%$ ) with different AD duration. Out of 53 patients with APS-1 without AD 29 (54.7\%) were positive for ACA and/or 21-OHAbs. Adrenal cortex autoantibody-positive patients were followed up for a mean period of 10 years (range $1-30$ years) and 25/29 (86.2\%) developed AD with an overall incidence of $\mathrm{AD}$ of $27 \%$ per year.

\section{Prevalence of other endocrine and non-endocrine autoimmune diseases at the onset of APS-1 and by the end of follow-up}

\section{Hypergonadotropic hypogonadism (HH)}

Females $\mathrm{HH}$, also known as premature ovarian failure (POF) in females, was found in one 30-year-old patient at the onset of APS-1. By the end of the follow-up, 51/103 females $(49.5 \%)$ developed POF at a mean age of $22 \pm 7.2$ (range 12-39 years) (Figs. 1, 2). In 43 patients (84\%), POF developed as secondary and in $8(16 \%)$ as primary amenorrhea. Two patients had Turner's syndrome. Steroid-producing cell autoantibodies (StCA) and/or $17 \alpha \mathrm{OH}$ autoantibodies $(17 \alpha \mathrm{OHAbs})$ and/or side-chain cleavage autoantibodies
(SCCAbs) were positive in 35/41 (85.4\%) patients with POF and in 24/42 (57.1\%) without POF. During follow-up, 10/24 (41.7\%) autoantibody-positive patients progressed to POF, with an overall incidence of $5.6 \%$ per year.

Males None of the males with APS-1 showed $\mathrm{HH}$ at the onset of APS-1. StCA and/or 17 $\alpha \mathrm{OHAbs}$ and/or SCCAbs were positive in $23 / 38(60.5 \%)$ tested without $\mathrm{HH}$. During a 7.6-year follow-up only one of the autoantibody-positive patients developed $\mathrm{HH}$ at the age of 16 years (after pubertal development).

\section{Autoimmune thyroid disease (AITD)}

Nine of 158 patients $(5.7 \%)$ were diagnosed with AITD at the onset of APS-1. In 4 patients (2.5\%), AITD was isolated, while in 5 (3.2\%), associated with other diseases and developed at a mean age of $14.8 \pm 6.2$ years (range 3-37 years). By the end of follow-up, 44/158 patients (27.8\%) developed AITD at a mean age of $18.6 \pm 13.4$ years (range $3-64$ years) (Figs. 1, 2). The majority, $41 / 44$ (93.2\%) presented with chronic thyroiditis (CT) while 3/44 (6.8\%) with Graves' disease (GD). At entry to follow-up, 10/30 (33.3\%) patients tested positive for thyroid autoantibodies had a subclinical hypothyroidism while 20/30 (66.7\%) had normal thyroid function. During follow-up, 6/20 thyroid autoantibodypositive patients $(30 \%)$ developed hypothyroidism, with an annual incidence of $4.5 \%$. 


\section{Type 1 diabetes mellitus (DM-1)}

Isolated DM-1 developed at the onset of APS-1 in 2/158 patients (1.3\%) (at 18 months and 39 years of age, respectively). By the end of the follow-up, 13/158 (8.2\%) patients developed DM-1 at a mean age of $18.1 \pm 12.6$ years (range 18 months-39 years) (Figs. 1,2). At the onset of DM-1, all affected patients were positive for glutamic acid decarboxylase autoantibodies (GADAbs) and/or islet cell autoantibodies (ICA). Furthermore, 18/64 patients (28.1\%) without DM-1 were found positive for ICA and/or GADAbs and during follow-up, the annual incidence of clinical DM-1 was $1.1 \%$.

\section{Pituitary insufficiency}

None of the 158 patients presented with pituitary insufficiency at the onset of APS-1. By the end of follow-up, $22 / 158(13.9 \%)$ developed pituitary insufficiency at a mean age of $13.7 \pm 8.1$ years (range $4-32$ years) (Figs. 1,2). Of these, 15 patients $(68.2 \%)$ had isolated growth hormone (GH) deficiency, 3 (13.6\%) diabetes insipidus, 1 (4.5\%) hypogonadotropic hypogonadism and 3 (13.6\%) had GH deficiency associated with hypogonadotropic hypogonadism. One out of four patients tested for pituitary autoantibodies was positive.

\section{Autoimmune gastritis (AG)/pernicious anemia (PA)}

At the onset of APS-1, AG was observed in one 4-year-old patient. However, 41/158 (25.9\%) patients developed AG at a mean age of $23 \pm 13$ years (range 4-56) by the end of follow-up (Figs. 1, 2). Macrocytic anemia suggesting PA was detected in 21/41 patients with AG and was diagnosed at a mean age of 18.5 years (Fig. 2). Out of 38 patients with AG tested for parietal cell autoantibodies (PCA), 27 (71\%) were positive. Intrinsic factor autoantibodies (IFA) were tested in 21 patients with PA and were positive in $13(62 \%)$.

\section{Vitiligo}

At the onset of APS-1, 3/158 (2\%) patients had vitiligo (isolated in one, associated with other diseases in two) that developed at a mean age of $4 \pm 1.7$ years. However, by the end of follow-up, vitiligo developed in 27 (17.1\%) subjects at a mean age of $17 \pm 15$ years (range 3-62 years) (Figs. 1, 2). Melanin-producing cell autoantibodies (MPCAbs) were found in 10/18 tested patients with vitiligo and in one without vitiligo who developed vitiligo 10 years later.

\section{Alopecia}

Only 3/158 (2\%) patients at the onset of APS-1 had alopecia which presented in association with other diseases at 3 years of age in all three subjects. In all, 38/158 (24\%) patients developed alopecia by the end of follow-up at a mean age of $13 \pm 10$ years (range $2-40$ years) (Figs. 1, 2).

\section{Celiac disease (CD)}

None of the 158 patients had CD at the onset of APS-1 while $4 / 158(2.5 \%)$ tissue transglutaminase autoantibodies-IgA (tTgAbs-IgA)-positive patients developed CD by the end of follow-up (Fig. 1).

\section{Autoimmune intestinal dysfunction (AID)}

Two APS-1 patients (1.3\%) manifested diarrhea or obstinate constipation, at the onset of APS-1; one had isolated AID diagnosed at 1 year of age, while the other presented at 32 years of age and had AID associated with other conditions. During the follow-up, 47/158 patients (29.7\%) developed AID at a mean age of $14.1 \pm 8.3$ years (range 1-32 years) (Figs. 1, 2). TPHAbs were positive in 31/37 $(83.8 \%)$ and AADC in 36/37 (97.3\%) patients with diarrhea or obstinate constipation. Gastric and duodenal biopsies in eight autoantibody-positive patients with diarrhea or obstinate constipation showed the presence of $\mathrm{CD}^{+} /$ $\mathrm{CD}^{+}$intraepithelial lymphocytes with a reduced number of enterochromaffin cells. The mean serum levels of serotonin in these patients were low of $0.16 \pm 0.14 \mu \mathrm{M} / \mathrm{L}$ (normal range: $0.28-1.7 \mu \mathrm{M} / \mathrm{L}$ ). The mean serotonin levels in other eight TPHAb-positive patients without diarrhea or obstinate constipation were within the lower levels of normal range at $0.58 \pm 0.41 \mu \mathrm{M} / \mathrm{L}$ suggesting a subclinical AID.

\section{Autoimmune hepatitis (AIH)}

AIH was diagnosed at the onset of APS- 1 in 4/158 patients (2.5\%) and was isolated in 3 patients while associated with other manifestations in one. The mean age at diagnosis was $2.8 \pm 2.2$ years. By the end of follow-up, 34 patients $(21.5 \%)$ developed $\mathrm{AIH}$ at a mean age of $13.1 \pm 9.2$ years (range 1-32 years) (Figs. 1, 2). Liver-kidney microsomal autoantibodies (LKMAbs) were positive in 13/24 patients (66.6\%) with AIH, while 3/7 patients (43\%) were positive for smooth muscle antibodies. The severity of the disease varied with some subjects having moderate to high levels of liver enzymes and responding to immunosuppression 
therapy while some $(n=4)$ progressing to acute fulminant hepatitis causing death.

\section{Autoimmune connective disease (ACD)}

None of the patients had ACD at the onset of APS-1. However, during follow-up, 9/158 (5.7\%) developed ACD at a mean age of $32 \pm 12$ years (range 10-47 years) (Figs. 1, 2). Six patients had Sjogren's syndrome, two rheumatoid arthritis, and one systemic scleroderma.

\section{Spleen atrophy (SA)}

None of the patients had SA at the onset of APS- 1 while during follow-up, SA was detected in $7 / 158$ patients $(4.4 \%)$ at a mean age of $25 \pm 10$ years (range 5-33 years) (Figs. 1, 2).

\section{Prevalence of other non-autoimmune diseases at the onset and by the end of follow-up}

Ectodermal dystrophy Keratoconjunctivitis (KC) was observed in one patient at the onset of APS- 1 and by the end of follow-up in 40/158 patients (25.3\%) at a mean age of $16 \pm 8$ years (range 2-36 years) (Figs. 1, 2). In addition, by the end of follow-up, enamel hypoplasia (EH) was noted in $28 / 158$ patients $(17.7 \%$ ) at a mean age of $9.8 \pm 3$ years (range 6-18 years) (Figs. 1,2) while 5/158 (3.2\%) patients had nail dystrophy (ND) (2 isolated and 3 associated with other disorders) at diagnosis of APS-1 at a mean age of 4.4 \pm 2.5 years (range $0.5-8$ years). By the end of follow-up, ND was present in 40/158 patients (25.3\%) and developed at a mean age of $10.9 \pm 6.7$ years (range $0.5-22$ years) (Figs. 1 , 2).

Cholelithiasis (Ch) Ch was diagnosed at the onset of APS-1 in one 23-year-old patient. During the follow-up, 11/158 patients $(7 \%)$ developed $\mathrm{Ch}$ at a mean age of $24 \pm 8$ years (range 11-27 years) (Figs. 1, 2).

Cancer During follow-up, 23/158 patients (14.5\%) developed 25 cancers at a mean age of $42 \pm 9.6$ years (range 24-68 years) (Figs. 1, 2). Of these, 7 patients had squamous cell carcinoma (SCC) of the oral mucosa, 1 had cancer of the tongue with local metastasis, 1 had cancer of the tongue and underwent tongue reconstructive surgery including quadriceps transplant, 1 patient with SCC of the tongue subsequently had peritoneal dissemination of gastric adenocarcinoma, 3 had esophageal cancer, 2 had gastric adenocarcinoma, 3 had large granular lymphocyte leukemia (LGLL) which in 1 patient was associated with pure red cell aplasia, 1 had a colorectal and a transverse colon adenocarcinoma, 1 had chronic lymphocytic leukemia, 1 had HIV-related Kaposi's sarcoma, 1 had melanoma and 1 had lip carcinoma.
Other very rare diseases Some of the patients in this study presented with other very rare diseases such as exocrine pancreas insufficiency, tubulointerstitial nephritis, hypopotassemia with apparent mineralocorticoid excess or sensitivity, deficit of IgA, metaphyseal dysplasia, vasculitis, autoimmune hemolytic anemia, cutaneous rash with fever, ocular myasthenia, obstructive pulmonary disease positive for potassium channel regulator autoantibodies (KCNRGAbs), psoriasis, pure red cell aplasia, posterior reversible encephalopathy syndrome, autoimmune demyelinating disease, cystic fibrosis, retinitis pigmentosa, chronic urticaria, lichen ruber planus, polyneuropathy, epilepsy, Hirschsprung's disease, renal agenesia, toxic epidermal necrolysis, $\mathrm{HCV}$ and autoimmune myocarditis.

Overall diseases in patients with APS-1 at the end of follow-up By the end of the mean $23.7 \pm 15.1$ years (range 1-67 years) of follow-up, 991 diseases were documented in the Italian cohort of APS-1 patients with a mean of 6.3 per patient, ranging widely from 1 to 16 diseases/patient (Fig. 4).

Mortality at the end of follow-up During the follow-up, $23 / 158(14.6 \%)$ patients died at a mean age of $35.8 \pm 21.3$ years (range 5-78), 8/23 (34.8\%) from cancers (2 from metastatic SCC of the oral mucosa, 3 gastric adenocarcinoma, 2 esophageal adenocarcinoma and 1 Kaposi's sarcoma) and 13/23 (56.5\%) from other diseases (4 fulminant AIH, 1 disseminated candidiasis, 1 cachexia, 1 adrenal crisis, 1 adrenal crisis during influenza with gastroenteritis, 1 brain hemorrhage, 1 pulmonary insufficiency, 1 Lyell's syndrome, 1 kidney insufficiency, and 1 cerebral stroke). In two patients (8.6\%), the cause of death was not defined. Mortality was significantly higher compared to the matched Italian population $(p<0.0001)$ [64] and greatly varied among patients from different geographical regions. In particular, during follow-up, 11/28 (39.3\%) patients died in North-East regions, 4/20 (20\%) in Apulia, 1/8 (12.5\%) in the South, $3 / 28(10.7 \%)$ in Sardinia, 2/20 (10\%) in Sicily, 1/15 (6.7\%) in Campania, and $1 / 44$ (2.3\%) in the other regions. Six patients reported a family history of an unexplained death of a sibling at a very young age.

\section{Prevalence of IFN $\omega$ Abs in patients with APS-1}

IFN $\omega$ Abs were positive in 103/113 (91.2\%) patients tested. However, the $10 \mathrm{IFN} \omega \mathrm{Ab}$-negative patients were tested after a mean period of 25 years from the onset of the disease.

\section{AIRE gene mutations}

In all, the 158 Italian patients were from 138 families, of which 120 families (87\%) had 1 affected member, while 18 


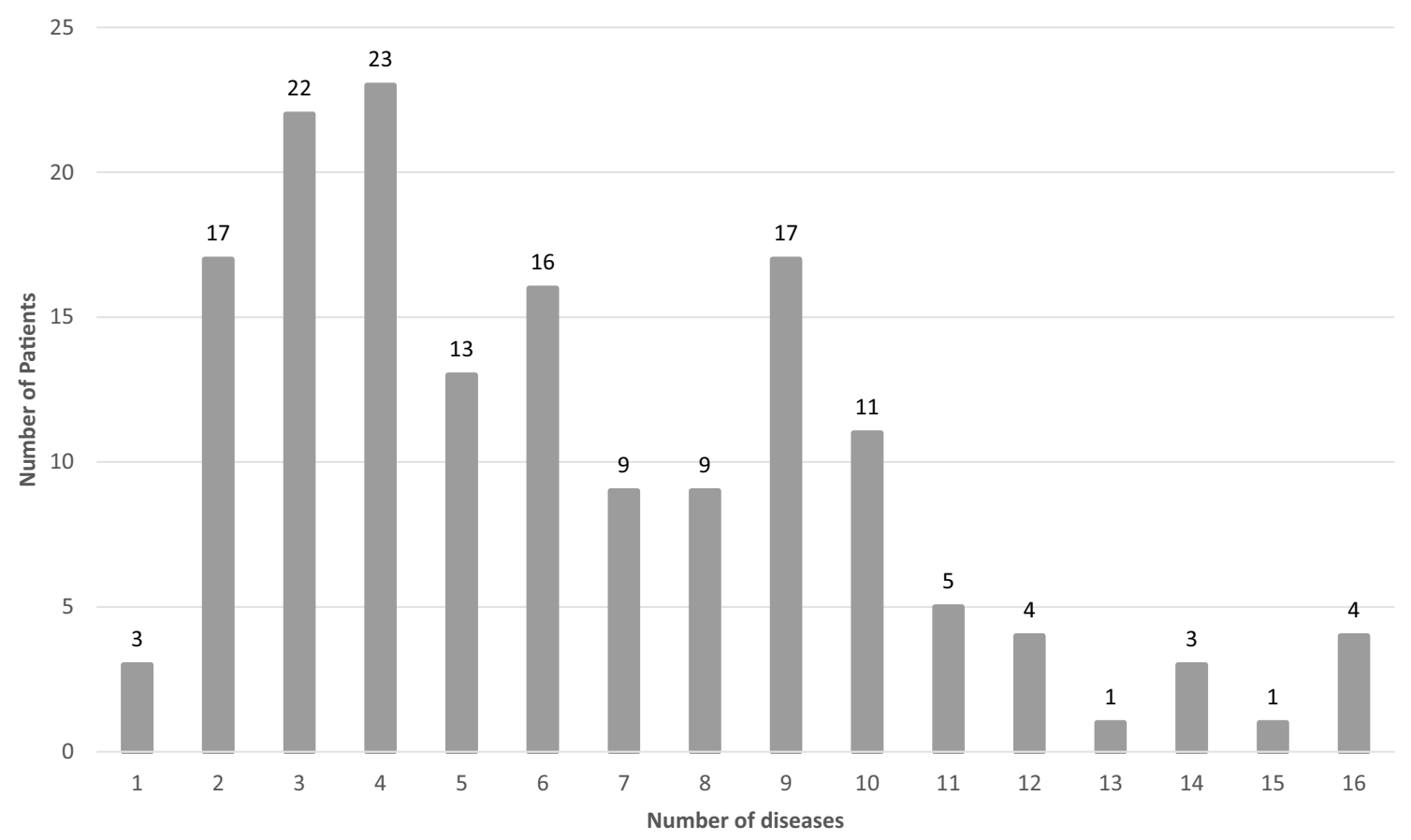

Fig. 4 Number of APS-1 patients in the Italian population who presented with 1-16 associated diseases

families (13\%) had more than 1 affected member; 2 in 17 families and in 1 family, 3/6 sisters were affected. Consanguinity between parents was found in 7/138 families (5\%). AIRE gene mutations were investigated in 272 alleles from 136 patients. In 22 patients, AIRE gene screening was not carried out due to the lack of consent or to the unavailability of samples. The results of the AIRE gene mutations are summarized in Table 3. Overall, 116/136 patients $(85.3 \%)$ had two homozygous or combined heterozygous mutations, $8(5.9 \%)$ had 1 mutation, $11(8 \%)$ had no mutations and 1 $(0.7 \%)$ had 3 mutations. One of the eight patients with only one mutation had a dominant mutation $(\mathrm{G} 228 \mathrm{~W})$ reported previously (41). The distribution of the AIRE gene mutations in relation to nine Italian geographical regions or macroareas from which the families originated is summarized in Fig. 5 and supplementary Table 1.

The most frequent mutation was $\mathrm{R} 139 \mathrm{X}$ detected in $58 / 272$ alleles $(21.3 \%$ ) (Table 4$)$. This mutation was almost exclusive 52/56 (93\%) alleles in Sardinian patients (Fig. 5 and Supplementary Table 1). R139X was inversely correlated to AITD $(p=0.02)$. R257X was detected in $32 / 272$ alleles (11.8\%) (Table 3) and was present predominantly in patients from North-East regions (48\%) and from Sicily (19\%) (Fig. 5 and Supplementary Table 1). This mutation was associated with AG $(p=0.03), \operatorname{PA}(p=0.04), \operatorname{AID}(p=$ $0.03)$, number of presented diseases $(p=0.04)$ and mortality $(p=0.03)$. W78R was found in $31 / 272$ alleles $(11.4 \%)$ (Table 3), mainly in patients from Apulia (54\%), southern (43\%) and central regions (25\%) (Fig. 5 and Supplementary
Table 1). W78R correlated with AD $(p=0.02)$, AITD $(p<$ $0.01)$, KC $(p<0.01)$, and $\mathrm{EH}(p<0.01)$. The less prevalent C322fsX372 mutation was detected in 24/272 alleles $(8.8 \%)$ (Table 4$)$, and present in patients from the North-East (25\%), North-West macro-areas (13\%) and mixed regions (19\%) (Fig. 5 and Supplementary Table 1). There was no correlation between genotype and phenotype for this mutation. Further, 17/272 alleles (6.2\%) carried T16M mutation (Table 3) which was found in patients from Campania (29\%) and central regions $(25 \%)$ and (Fig. 5 and Supplementary Table 1) and showed correlation with CMC ( $p=$ $0.03)$. R203X was detected in 11/272 alleles (4\%) of Italian patients (Table 3), was present in Sicily (25\%) and in the south regions (14\%) (Fig. 5 and Supplementary Table 1) and was significantly associated with AITD $(p=0.03)$ and inversely associated with cholelithiasis $(p=0.01)$. A21V was detected in $8 / 272$ alleles $(2.9 \%)$ and found in Sicily (13\%) (Table 3). Of rare mutations, 4/272 alleles (1.5\%) carried 1085-1097-del, IVS13+2insT, IVS1+5delG and P539L, respectively, L87P was carried in 3/272 alleles (1.1\%), and S196S, C311fsX377, c.965_977del13, C1314-1326del13/ insGT, and c834 were carried in 2 alleles $(0.7 \%)$, respectively (Table 3 ). Very rare mutations were found in other 26/272 (9.6\%) alleles. One patient from Sicily had three mutations T16M/S107C, Q108sf (Fig. 5 and Supplementary Table 1) of which S107C and Q108fs are mutations located in exon 3 previously described $[51,52]$. A patient from Campania had a homozygous mutation c1314-1326del13insGT described previously [46]. 


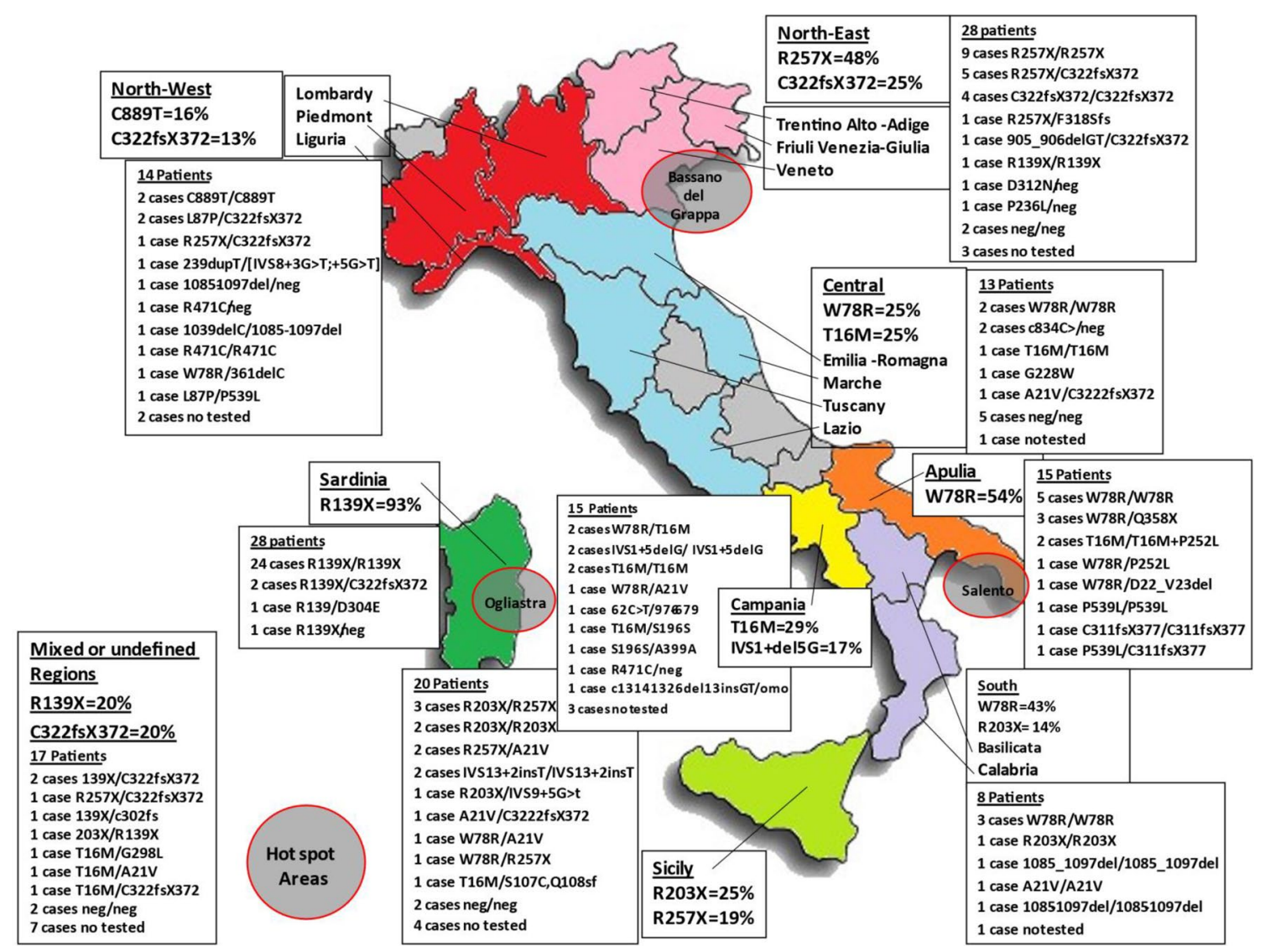

Fig. 5 AIRE gene mutations in APS-1 patients in different macro-areas or regions of Italy

Two pairs of siblings who carried the same homozygous mutation presented with distinctly different phenotypes. One pair of a 17-year-old male and 15-year-old female from Campania both had homozygous IVS1+5delG mutation and while the male presented 16 different diseases, the female was affected by only 4 conditions. A different pair from Calabria carried homozygous W78R mutation and a 22-year-old brother presented with 5 different diseases while his 15 -year-old sister had 9 different diseases.

\section{Discussion}

Our study describes 158 well-characterized Italian patients with APS-1 who represent the largest one nation cohort of patients with APS-1 published to date. Previously large cohorts of 91 Finnish [15] or 112 Russian patients have been reported [33]. In all 568, APS-1 patients from 20 different cohorts have been described previously (Table 1 and supplementary Figure 1) and with addition of 158 patients from our study the total number of well-characterized patient cohorts with APS-1 has reached 726. In addition to the cohort studies, there are a number of case reports on the individual or familial presentations of APS-1 in different countries. Therefore, the overall number of APS-1 patients worldwide could be estimated at approximately 1000 individuals. In our study, patients were recruited from specialist endocrine centers across Italy allowing for the first time an estimate of the prevalence of APS-1 in Italy at 2.6 cases/million, i.e., approximately 1 case per 384,615 individuals. Although the number of patients enrolled was relatively high, the prevalence of APS-1 in Italy is lower than in Iranian Jews, Finland, Norway, Poland and Ireland $[1,5-11,15,20]$ while higher than in France and Japan. Our study showed large variations in the prevalence of APS-1 in different regions of Italy. For example, the highest prevalence was noted in Sardinia with 17 cases/million ( 1 case per 58,823 inhabitants), followed by Veneto with 4.7 , Sicily with 3.9 and Apulia with 3.7 cases/million, respectively. In contrast, lower prevalence (0.6- 0.5 cases/million) was observed in the other regions (Table 2). Furthermore, three "hot spot areas" for APS-1 were identified in Italy (Fig. 5), and in those areas AIRE gene screening in the healthy population would be helpful in detecting asymptomatic carriers who could then be offered appropriate genetic counseling. 
Table 4 AIRE gene mutations in the Italian population with APS-1

\begin{tabular}{ll}
\hline AIRE gene mutations & Alleles affected (\%) \\
\hline R139X & $58 / 272(21.3 \%)$ \\
R257X & $32 / 272(11.8 \%)$ \\
W78R & $31 / 272(11.4 \%)$ \\
C322fsX372 & $24 / 272(8.8 \%)$ \\
T16M & $17 / 272(6.2 \%)$ \\
R203X & $11 / 272(4.0 \%)$ \\
A21V & $8 / 272(2.9 \%)$ \\
Less frequent & $35 / 272(12.9 \%)$ \\
R471C & $4 / 272(1.5 \%)$ \\
1085-1097del & $4 / 272(1.5 \%)$ \\
IVS13+2insT & $4 / 272(1.5 \%)$ \\
IVS1 + 5delG & $4 / 272(1.5 \%)$ \\
P539L & $4 / 272(1.5 \%)$ \\
C889T & $4 / 272(1.5 \%)$ \\
L87P & $3 / 272(1.1 \%)$ \\
S196S & $2 / 272(0.7 \%)$ \\
C311fsX377 & $2 / 272(0.7 \%)$ \\
C1314-1326del/insGT & $2 / 272(0.7 \%)$ \\
C834C $>$ G & $2 / 272(0.7 \%)$ \\
Very rare & $26 / 272(9.6 \%)$ \\
No mutations on both alleles in 11 patients and & $30 / 272(10.7 \%)$ \\
no mutation in 1 allele in other 8 cases & \\
\hline
\end{tabular}

In this study, more than $93 \%$ of patients presented with one of the classical triad diseases at onset while $7 \%$ manifested with other diseases. A similar clinical presentation has been described in European populations [5, 15]. However, in the cohorts of American patients [17, 35], non-major component diseases were noted at APS-1 onset in 40-80\% of the cases.

In the majority of our Italian patients who presented with the classical triad at onset, the first most frequently manifesting disease was $\mathrm{CMC}$ followed by $\mathrm{CH}$ and then $\mathrm{AD}$. However, by the end of a long follow-up, the most frequent disease was $\mathrm{CH}$ diagnosed in $86 \%$ of the patients at a mean age of 11 years, followed by $\mathrm{AD}$ in $77 \%$ of the patients at a mean age of 16.3 years and CMC in $76 \%$ of the patients which presented at a younger mean age of 9.1 years. The highest prevalence of $\mathrm{CMC}, \mathrm{CH}$ and $\mathrm{AD}$ was in patients from the South and Apulia and the lowest from the central regions (Fig. 3). These differences may be related to the differences in genetic background of populations in these regions. Subsequent to initial presentation of the three major manifestations of APS-1, many other autoimmune and nonautoimmune diseases developed throughout patients' lives. APS-1 is a most complex and puzzling autoimmune syndrome due to the great variety and severity of autoimmune and non-autoimmune comorbidities. In our cohort, patients manifested in total 991 diseases with an average of 6.3 conditions per patient. However, 4 exceptional patients in our study developed up to 16 diseases per patient representing the highest co-morbidity in APS-1 reported to date [19].

IFN $\omega \mathrm{Abs}$ were found to be the best serological marker of APS-1 regardless of the comorbidities and the duration of the syndrome as previously described [4, 20, 33-35, 48]. This confirms that IFN $\omega$ Abs are a diagnostic marker for APS-1 and can be particularly helpful in early diagnosis in patients presenting with a single manifestation of APS-1 [4].

Patients in our study developed cancers at a relatively young age of which approximately half were SCC of the mouth, tongue, esophagus, probably related to the $\mathrm{CMC}$ or gastric adenocarcinoma probably related to $\mathrm{AG}$ and this is consistent with previous reports [65]. In the case of other cancers, LGLL is a monoclonal lymphoproliferative disease characterized by persistent and indolent lymphocytosis described in only 0.2 and 0.7 cases/million in the USA and Netherlands, respectively [64], and associated with autoimmune diseases (rheumatoid arthritis, Sjogren's syndrome, autoimmune cytopenia, hemolytic anemia, or thrombocytopenia) [66, 67]. In our study, LGLL was found in 3/158 (1.9\%) of APS-1 patients and this represent the highest frequency of this disorder in an autoimmune syndrome. Only two case reports of LGLL in APS-1 were published so far $[68,69]$. Finally, one exceptional case developed two adenocarcinomas of the colon not previously reported in this syndrome.

The mortality in APS-1 patients was significantly higher compared to the general Italian population [64] in agreement with previous reports on European [20, 70-72] and non-European cohorts $[34,35]$. Mortality was highest in the North-East regions compared to the other regions in Italy. In approximately one-third of our patients, death was caused by malignancies while in the other two-third causes were adrenal crises, fulminant hepatitis, or generalized candidiasis.

In addition to IFN $\omega \mathrm{Abs}$, we have also assessed the value of other serological markers of autoimmune diseases. We confirmed the role of NALP-5Abs as markers of $\mathrm{CH}$; however, this test is not widely available outside research laboratories [61]. ACA and/or 21-OHAbs showed excellent diagnostic sensitivity and were detected in the great majority of APS-1 patients with AD within 2 years of onset. Furthermore, they were also found in approximately half of APS- 1 patients without AD and conferred a high risk (86.2\%) of progression to AD in APS-1 compared to a low risk $(25 \%)$ in patients with other types of APS [73]. As AD in APS- 1 tends to develop after CMC and/or $\mathrm{CH}$, it would seem appropriate to test for ACA and/or 21-OHAbs in all patients with $\mathrm{CMC}$ and/or $\mathrm{CH}$. This strategy would alert physicians to the high probability of progression to clinical $\mathrm{AD}$ for patients positive for these autoantibodies and would be helpful in preventing unexpected life-threatening adrenal crisis events [74]. 
Nearly, half of the females with APS-1 in our cohort developed POF (Fig. 1). This is in agreement with previous cohort studies where POF was among the most frequent of the non-classical components of APS-1 (Table 1 and supplementary Figure 1). In our study, the great majority of the patients with POF were positive for StCA and/or 17 $\alpha \mathrm{OHAbs}$ and/or SCCAbs which are considered diagnostic for autoimmune oophoritis without the need for ovarian biopsy or further genetic investigations [75-77]. Furthermore, approximately half of the young females with APS- 1 who had normal menses and were positive for StCA and/or 17 $\alpha \mathrm{OHAbs}$ and/or SCCAbs developed POF during follow-up with an annual incidence of $5.6 \%$. This confirmed that these autoantibodies are also good predictive markers of POF [77]. In addition, StCA, and/or 17 $\alpha \mathrm{OHAbs}$ and/or SCCAbs were positive in $60 \%$ of the males with APS- 1 of whom none had $\mathrm{HH}$ at the time of testing and during the follow-up only one patient developed HH. Consequently, in this study, positivity for autoantibodies to steroid-producing cells/steroidogenic enzymes was associated with a very different risk of $\mathrm{HH}$ in females and males in agreement with previous studies [77, 78].

Almost one-third of APS-1 patients had AITD which presented in most cases as CT and only exceptionally as GD consistent with previous reports [15]. Some patients with normal thyroid function were positive for thyroid autoantibodies at entry into the study and during the follow-up, developed hypothyroidism with an annual incidence of $4.5 \%$. This would suggest that thyroid autoantibodies could be considered as markers of progressing to thyroid dysfunction also in APS-1.

During the follow-up, a third of the patients with APS-1 manifested diarrhea or constipation and the great majority of them were positive for TPHAbs and/or AADCAbs. These Abs correlated with lymphocytic infiltration of the gastric and duodenal mucosa, reduced number of enterochromaffin cells and with the low serum serotonin levels consistent with AID. Our study also confirmed that TPHAbs and/ or AADCAbs are markers of a subclinical AID as reported previously $[79,80]$.

In cohorts described previously to date, $3-33 \%$ of patients with APS-1 had DM-1 (Table 1 and supplementary Figure 1). In our cohort, DM-1 was found in $8 \%$ of patients who were all positive for diabetes-associated autoantibodies. This represents one of the lowest co-occurrences of DM-1 and APS-1 reported thus far. Although 28\% of our APS-1 patients without DM-1 were positive for ICA and/or GADAbs the annual risk of developing clinical DM-1 at the end of follow-up was very low (1\%) compared to patients with other autoimmune diseases [81] or to healthy children [82]. This difference risk may be related to the absence of specific HLA genotypes predisposing to DM-1 in our APS-1 patients. In addition, GADAbs in patients with APS-1 may recognize different epitopes compared to those recognized by patients with DM-1 without APS-1 [83].

AG was observed in a quarter of our patients and a half of these manifested with PA at a very young age although PA usually manifests in elderly individuals. In addition, onefifth of the APS-1 patients had AIH occurring at a mean age of 13 years. The majority of our patients were responsive to immunosuppression therapy but four patients died from fulminant hepatitis. CD has been reported in 5-14\% of APS-1 patients in different cohorts (Table 1 and Supplementary Figure 1) while in our study, only $3 \%$ of patients were affected by CD which may be related to the absence of HLA genes predisposing to $\mathrm{CD}$ in our population.

Our study shows that patients with APS- 1 exhibit a wide range of specific autoimmune disorders some of which are rare. Autoantibody tests for these rare conditions are often unavailable in routine diagnostic laboratories and it would be appropriate that these should be provided by specialized, designated reference laboratories in different countries to assist in a complete diagnostic work-up of APS-1.

In this study, $13 \%$ of families had at least one other family member with APS- 1 and this is one of the highest prevalence of the same autoimmune syndrome in non-twin relatives. It is consistent with the high genetic risk for APS-1 associated with AIRE gene mutations. Consanguinity of parents was found in $5 \%$ of families in our study in contrast to earlier reports on different populations $[6,31]$.

Our cohort of patients displayed different AIRE gene mutations some of which were clustered in different geographical regions. This differs from the Finnish, Iranian Jewish or other populations where one specific mutation was predominantly found in the great majority of patients $[6,15]$. In Italy, the most prevalent mutation was R139X detected in $21.5 \%$ of the alleles overall; however, it was predominant in Sardinia being present in $95 \%$ of patients. The next most prevalent mutation was R257X found in $11.8 \%$ of alleles overall while being the most frequent in Veneto and North-East areas. R257X mutation is the most common among the Finnish APS-1 population [15]. In our cohort, W78R was found in $11.5 \%$ of the alleles overall and it was carried by most of the patients from Apulia where it was first detected [42] and in the south of Italy. C322fsX372 was found in $8.1 \%$ of APS- 1 patients typically in the Veneto and North-East populations. This is a common mutation in patients with an Anglo-Saxon background [21]. In our study, we have identified three novel mutations: S107C and Q108fs on exon 3 in patients from Sicily and c1314-1326del13insGT in a patient from Campania. In our study, 8 patients had only one allelic mutation as reported in other populations [33]. Seven of these had one non-dominant mutation while one patient from central Italy had a dominant mutation G228W described previously [41, 84]. The only other dominant mutation 
associated with APS-1 reported to date was p.C311Y (p932G $>A$ ) found in a patient from North Africa [85]. The relatively wide variations in AIRE gene mutations among Italian APS-1 patients may reflect the heterogeneity of the founder genes derived from different migrant populations passing through or settling and living in Italy over time. Furthermore, this study found that some of the mutations were typical for specific geographical regions of Italy. Therefore, recording a detailed family history is essential for patients being tested for AIRE gene mutations. In our study, 10 APS- 1 patients had no detectable mutations in the AIRE gene in agreement with other populations [15, 84] and this suggests that not yet identified genes could be involved in the development of APS-1. The AIRE gene is strongly implicated in the regulation of organ-specific antigen expression in medullary thymic epithelial cells and in the $\mathrm{T}$ cell tolerance [4, 19]. However, as suggested by [86], although AIRE is an important transcriptional controller, other controllers should work independently in promiscuous gene expression (PGE). In the light of the foregoing, on a speculative basis, it may be suggested that defects of AIRE partners or of other PGE controllers could be responsible for the development of clinical APECED manifestations in patients that do not harbor AIRE gene mutations. In future studies, on exome sequencing may be useful in extending our understanding of the genetic causes of APS1. In previous studies, a correlation between genotype and phenotype has been reported in some patients with APS-1 $[6,20]$. For example, in the Norwegian population some gene deletions were associated with the onset of APS-1 later in life and a milder phenotype while some genotypes which lead to formation of truncated proteins appeared to be associated with CMC and AD [20]. In contrast, some patients carrying the same mutation (even siblings) presented different clinical manifestations and experienced different courses of the disease $[18,87]$. Among our Italian patients, there were some direct genotype-phenotype associations for R139X, R257X, W78R, T16M and R203X. However, some siblings in our study harboring the same AIRE mutation presented remarkably different phenotypes. This suggests that in addition to key AIRE gene mutation other genetic, environmental or stochastic factors may impact on the phenotypic expression of APS-1 [20].

Overall, our study is a detailed analysis of all available information on the largest cohort to date of patients with APS-1 from a single national population. As such, this study should enhance the current understanding of the complexity of APS-1 and help in the diagnosis and management of this rare disease ultimately benefiting the affected patients and their families.

Supplementary Information The online version contains supplementary material available at https://doi.org/10.1007/s40618-021-01585-6.
Acknowledgements We would like to thank all the Italian patients with APS-1 who have given their consent to participate in this study. For contributions to the collection of clinical data and/or blood and/or DNA samples of some patients with APS-1 are gratefully acknowledged: Mauro Alaibac (Padova), Antonio Balsamo (Bologna), Giuseppe Bellastella (Napoli), Antonio Caretto (Brindisi), Alessandra Cassio (Bologna), Maria del Pilar Larosa (London), Giuseppe Delitala (Sassari), Filippo De Luca (Messina), Serena Demattè (Trento), Natascia Di Iorgi (Genova), Alberto Falorni (Perugia), Piernicola Garofalo (Palermo), Lucia Ghizzoni (Torino), Roberta Giordano (Torino), Luca Manetti (Pisa), Stefano Mariotti (Cagliari), Valentina Morelli (Milano), Patrizia Matarazzo (Torino), Giuseppe Picca (Foggia), Gianni Russo (Milano), Paola Sartorato (Treviso), Marina Scarlato (Milano), Maria Simoncini (Vicenza), Antonio Tonini (Trieste), and Renato Zambello (Padova).

Funding Open access funding provided by Università degli Studi di Padova within the CRUI-CARE Agreement. The study was partially funded from the EU Sixth Framework Programme EURAPS: Autoimmune Polyendocrine Syndrome type 1 a rare disorder of childhood as a model for Autoimmunity. Grant No. 2006-005223; and from the EU Seventh Framework Programme, EURADRENAL: Pathophysiology and Natural Course of Autoimmune Adrenal Failure in Europe. Grant $\mathrm{N}^{\circ} 2008-201167$.

\section{Declarations}

Conflict of interest SC, BRS, JF, and SKB are employees of RSR Ltd. RSR Ltd is a developer of medical diagnostics including assays and/ or kits for measuring 21-OH Abs, $17 \alpha$-hydroxylase Abs, side-chain cleavage enzyme Abs, tryptophan hydroxylase Abs, interferon- $\omega$ Abs, aromatic-L-aminoacid-decarboxylase Abs, and TSH-Receptor Abs.

Research involving human participants and/or animals This study does not contain any studies with animals performed by any of the authors.

Informed consent Informed consent was obtained from all individual participants included in the study.

Open Access This article is licensed under a Creative Commons Attribution 4.0 International License, which permits use, sharing, adaptation, distribution and reproduction in any medium or format, as long as you give appropriate credit to the original author(s) and the source, provide a link to the Creative Commons licence, and indicate if changes were made. The images or other third party material in this article are included in the article's Creative Commons licence, unless indicated otherwise in a credit line to the material. If material is not included in the article's Creative Commons licence and your intended use is not permitted by statutory regulation or exceeds the permitted use, you will need to obtain permission directly from the copyright holder. To view a copy of this licence, visit http://creativecommons.org/licenses/by/4.0/.

\section{References}

1. Ahonen P, Myllarniemi S, Sipila I, Perheentupa J (1990) Clinical variation of autoimmune polyendocrinopathy-candidiasis-ectodermal dystrophy (APECED) in a series of 68 patients. N Engl J Med 322:1829-1836

2. Betterle C, Presotto F (2008) Autoimmune polyendocrine syndromes (aps) or multiple autoimmune syndromes (MAS). In: Walker S, Jara LJ (eds) Handbook of systemic autoimmune 
diseases. Endocrine manifestations of systemic autoimmune diseases, vol 9. Elsevier, Amsterdam, pp 135-148

3. Betterle C, Sabbadin C, Scaroni C, Presotto F (2019) Autoimmune polyendocrine syndromes (APS) or multiple autoimmune syndromes (MAS) an overview. In: Colao AM, Jaffrain-Rea ML, Beckers A (eds) Polyendocrine disorders and endocrine neoplastic syndromes. Endocrinology. Springer Nature, Switzerland AG, pp 1-50. https://doi.org/10.1007/978-3-319-73082

4. Husebye ES, Anderson MS, Kampe O (2018) Autoimmune polyendocrine syndromes. N Engl J Med 378:1132-1141

5. Guo CJ, Leung PSC, Zhang W, Ma X, Gershwin ME (2018) The immunobiology and clinical features of type 1 autoimmune polyglandular syndrome (APS-1). Autoim Rev 17:78-85

6. Zlotogora J, Shapiro MS (1992) Polyglandular autoimmune syndrome type I among Iranian Jews. J Med Genet 29:824-826

7. Wolff ASB, Erichsen MM, Meager A et al (2007) Autoimmune polyendocrine syndrome type 1 in Norway: phenotypic variation, autoantibodies, and novel mutations in the autoimmune regulator gene. J Clin Endocrinol Metab 92:595-603

8. Stolarski B, Pronicka E, Korniszewski L et al (2006) Molecular background of polyendocrinopathy-candidiasis-ectodermal-dystrophy syndrome in a Polish population: novel AIRE mutations and an estimate of disease prevalence. Clin Genet 70:348-354

9. Dominguez M, Crushell E, Ilmarinen T et al (2006) Autoimmune polyendocrinopathy-candidiasis-ectodermal dystrophy (APECED) in the Irish population. J Pediatr Endocrinol Metab 19:1343-1352

10. Proust-Lemoine E, Saugier-Veber P, Wémeau JL (2012) Polyglandular autoimmune syndrome type I. Presse Med 41:e651-662

11. Sato U, Horikawa R, Katsumata N, Asakura Y, Kitanaka S, Tanaka T (2004) Novel compound heterozygous AIRE mutations in a Japanese patient with APECED. J Pediatr Endocrinol Metab 17:917-921

12. Neufeld M, Blizzard RM (1980) Polyglandular autoimmune diseases. In: Pinchera A, Doniach D, Fenzi GF, Baschieri L (eds) Symposium on autoimmune aspects of endocrine disorders. Academic Press, New York, pp 357-365

13. Betterle C, Dal Pra C, Mantero F, Zanchetta R (2002) Autoimmune adrenal insufficiency and autoimmune polyglandular syndrome: autoantibodies, autoantigens and their applicability in diagnosis and disease prediction. Endocrine Rev 23:327-364

14. Husebye ES, Perheentupa J, Rautemaa R, Kampe O (2009) Clinical manifestations and management of patients with autoimmune polyendocrine syndrome type I. J Intern Med 265:514-529

15. Perheentupa $\mathbf{J}$ (2006) Autoimmune polyendocrinopathy-candidiasis-ectodermal dystrophy. J Clin Endocrinol Metab 912:843-855

16. Capalbo D, Improda N, Esposito A et al (2013) Autoimmune polyendocrinopathy-candidiasis-ectodermal-dystrophy from the pediatric perspective. J Endocrinol Invest 36:903-912

17. Ferre EM, Rose SR, Rosenzweig SD et al (2016) Redefined clinical features and diagnostic criteria in autoimmune polyendocrinopathy-candidiasis-ectodermal-dystrophy. JCI Insight 1:e88782. https://doi.org/10.1172/jci.insight.88782

18. Weiler FG, Dias-da-Silva MR, Lazaretti-Castro M (2012) Autoimmune polyendocrine syndrome type 1: case report and review of literature. Arq Bras Endocrinol Metab 56:54-66

19. Fierabracci A (2011) Recent insights into the role and molecular mechanisms of the autoimmune regulator (AIRE) gene in autoimmunity. Autoimmun Rev 10:137-143

20. Bruserud O, Oftedal BE, Wolff AB, Husebye ES (2016) AIREmutations and autoimmune disease. Curr Opin Immunol 43:8-15

21. Passos GA, Speck-Hernandez CA, Assis AF, Mendes-da-Cruz DA (2018) Update on Aire and thymic negative selection. Immunology 153:10-20

22. Cervato S, Mariniello B, Lazzarotto F et al (2009) Evaluation of the autoimmune regulator (AIRE) gene mutations in a cohort of Italian patients with autoimmune-polyendocrinopathy-candidiasis-ectodermal-dystrophy (APECED) and in their relatives. Clin Endocrinol 70:421-428

23. De Martino L, Capalbo D, Improda N et al (2013) APECED: a paradigm of complex interactions between genetic background and susceptibility factors. Front Immunol 4:86

24. Pearce SH, Cheetham T, Imrie H et al (1998) Common and recurrent 13-bp deletion in the autoimmune regulator gene in British kindreds with autoimmune polyendocrinopathy type 1 . Am J Hum Genet 63:1675-1684

25. Wang CY, Davoodi-Semiromi A, Huang W, Connor E, Shi JD, She JX (1998) Characterization of mutations in patients with autoimmune polyglandular syndrome type 1 (APS1). Hum Genet 103:681-685

26. Betterle C, Greggio NA, Volpato M (1998) Autoimmune polyglandular disease type 1. J Clin Endocrinol Metab 83:1049-1055

27. Cihakova D, Trebusak K, Heino M et al (2001) Novel AIRE mutations and P450 cytochrome autoantibodies in Central and Eastern European patients with APECED. Hum Mutat 18:225-232

28. Podkrajsek KT, Milenovic T, Odink RJ et al (2008) Detection of a complete autoimmune regulator gene deletion and two additional novel mutations in a cohort of patients with atypical phenotypic variants of autoimmune polyglandular syndrome type 1. Eur J Endocrinol 159:633-639

29. Magitta FN, Pura M, Bøe Wolff AS et al (2008) Autoimmune polyendocrine syndrome type I in Slovakia: relevance of screening patients with autoimmune Addison's disease. Eur J Endocrinol 158:705-709

30. Tóth B, Wolff AS, Halász Z et al (2010) Novel sequence variation of AIRE and detection of interferon-omega antibodies in early infancy. Clin Endocrinol (Oxf) 72:641-647

31. Bin-Abbas BS, Faiyaz-Ul-Haque M, Al-Fares AH, Al-Gazlan SS, Bhuiyan JA, Al-Muhsen SZ (2010) Autoimmune polyglandular syndrome type 1 in Saudi children. Saudi Med J 31:788-792

32. Millar S, Carson D (2012) Clinical phenotypes of autoimmune polyendocrinopathycandidiasis-ectodermal dystrophy seen in the Northern Ireland paediatric population over the last 30 years. Ulster Med J 81:118-122

33. Orlova EM, Sozaeva LS, Kareva MA et al (2017) Expanding the phenotypic and genotypic landscape of autoimmune polyendocrine syndrome type 1. J Clin Endocrinol Metab 102:3546-3556

34. Zaidi G, Bhatia V, Sahoo SK et al (2017) Autoimmune polyendocrine syndrome type 1 in an Indian cohort: a longitudinal study. Endocr Connect 6:289-296

35. Weiler FG, Peterson P, Costa-Carvalho BT et al (2018) The heterogeneity of autoimmune polyendocrine syndrome type 1: clinical features, new mutations and cytokine autoantibodies in a Brazilian cohort from tertiary care centers. Clin Immunol 197:231-238

36. Del Prete GF, Bottazzo GF, Betterle C, Bersani G, Trisotto A (1975) Poliendocrinopatia autoimmune. Stud Immunol Folia Allerg Immunol Clin 22:123-129

37. Pocecco M, Saletta S, Nassinbeni G, Betterle C (1995) Sindrome poliendocrina autoimmune e candidiasi cronica mucocutanea (SPA tipo I). Prospet Pediatr 25:33-45

38. Rosatelli MC, Meloni A, Devoto M et al (1998) A common mutation in Sardinian autoimmune polyendocrnopathy-candidiasisectodermal dystrophy patients. Hum Genet 103:428-434

39. Scott HS, Heino M, Peterson P et al (1998) Common mutations in autoimmune polyendocrinopathy-candidiasis-ectodermal dystrophy patients of different origins. Mol Endocrinol 12:1112-1119

40. Perniola R, Falorni A, Clemente MG, Forini F, Accogli E, Lobreglio G (2000) Organ-specific and non-organ-specific autoantibodies in children and young adults with autoimmune polyendocrinopathy-candidiasis-ectodermal dystrophy (APECED). Eur J Endocrinol 143:497-503

41. Cetani F, Barbesino G, Borsari S et al (2001) A novel mutation of the autoimmune regulator gene in an Italian kindred with 
autoimmune polyendocrinopathy-candidiasis-ectodermal dystrophy, acting in a dominant fashion and strongly cosegregating with hypothyroid autoimmune thyroiditis. J Clin Endocrinol Metab 86:4747-5452

42. Meloni A, Perniola R, Faà V, Corvaglia E, Cao A, Rosatelli MC (2002) Delineation of the molecular defects in the AIRE gene in autoimmune polyendocrinopathy-candidiasis-ectodermal dystrophy patients from Southern Italy. J Clin Endocrinol Metab 87:841-846

43. Buzi F, Badolato R, Mazza C et al (2003) Autoimmune polyendocrinopathy-candidiasis-ectodermal dystrophy syndrome: time to review diagnostic criteria? J Clin Endocrinol Metab 88:3146-3148

44. Porzionato A, Zancaner S, Betterle C, Ferrara SD (2004) Fatal toxic epidermal necrolysis in autoimmune polyglandular syndrome type 1. J Endocrinol Invest 27:475-479

45. Capalbo D, Elefante A, Spagnuolo MI et al (2008) Posterior reversible encephalopathy syndrome in a child during an accelerated phase of a severe APECED phenotype due to an uncommon mutation of AIRE. Clin Endocrinol (Oxf) 69:511-513

46. Lintas C, Cappa M, Comparcola D, Nobili V, Fierabracci A (2008) An 8-year-old boy with autoimmune hepatitis and Candida onychosis as the first symptoms of autoimmune polyglandular syndrome (APS1): identification of a new homozygous mutation in the autoimmune regulator gene (AIRE). Eur J Pediatr 167:949-953

47. Mazza C, Buzi F, Ortolani F, Vitali A et al (2011) Clinical heterogeneity and diagnostic delay of autoimmune polyendocrinopathy-candidiasis-ectodermal dystrophy syndrome. Clin Immunol 139:6-11

48. Meloni A, Willcox N, Meager A et al (2012) Autoimmune polyendocrine syndrome type 1: an extensive longitudinal study in Sardinian patients. J Clin Endocrinol Metab 97:1114-1124

49. Valenzise M, Wasniewska M, Mirabelli S, De Luca F, Cervato S, Betterle C (2012) Identification of two novel mutations in the first Sicilian APECED patient with no R203X mutation in AIRE gene and review of Italian APECED genotypes. Gene 499:343-346

50. Betterle C, Ghizzoni L, Cassio A et al (2012) Autoimmune-polyendocrinopathy-candidiasis-ectodermal-dystrophy in Calabria: clinical, immunological and genetic patterns. J Endocrinol Invest 35:877-881

51. Giordano C, Modica R, Allotta ML et al (2012) Autoimmune polyendocrinopathy-candidiasis-ectodermal-dystrophy (APECED) in Sicily: confirmation that R203X is the peculiar AIRE gene mutation. J Endocrinol Invest 35:384-388

52. Valenzise M, Fierabracci A, Cappa M et al (2014) Autoimmune polyendocrinopathy-candidiasis-ectodermal dystrophy: report of seven additional Sicilian patients and overview of the overall series from sicily. Horm Res Paediatr 82:127-132

53. Betterle C, Salvà M, Sabbadin C, Garelli S (2016) La sindrome poliendocrina autoimmune di tipo 1 in Italia. L' Endocrinologo 17:10-20. https://doi.org/10.1007/s40619-016-0169-y

54. Husebye ES, Perheentupa J, Rautemaa R, Kämpe O et al (2009) Clinical manifestations and management of patients with autoimmune polyendocrine syndrome type I. J Intern Med 265:514-529

55. Chen S, Sawicka J, Betterle C et al (1996) Autoantibodies to steroidogenic enzymes in autoimmune polyglandular syndrome, Addison's disease, and premature ovarian failure. J Clin Endocrinol Metab 83:2977-2986

56. Tanaka H, Perez MS, Powell M et al (1997) Steroid 21-hydroxylase autoantibodies: measurements with a new immunoprecipitation assay. J Clin Endocrinol Metab 82:1440-1446

57. Betterle C, Volpato M, Pedini B, Rees Smith B, Furmaniak J (1999) Adrenal-cortex autoantibodies and steroid producing cells autoantibodies in patients with Addison's disease: comparison of immunofluorescence and immunoprecipitation assays. J Clin Endocrinol Metab 84:618-622
58. Cervato S, Morlin L, Albergoni MP et al (2010) AIRE gene mutations and autoantibodies to interferon omega in patients with chronic hypoparathyroidism without APECED. Clin Endocrinol 73:630-636

59. Dal Pra C, Chen S, Betterle C et al (2004) Autoantibodies to human tryptophan hydroxylase and aromatic L-amino acid decarboxylase. Eur J Endocrinol 150:313-321

60. Basso D, Guariso G, Fasolo M et al (2006) A new indirect chemiluminescent immunoassay to measure anti-tissue transglutaminase antibodies. J Ped Gastroenterol Nutr 43:613-618

61. Alimohammadi M, Björklund P, Hallgren A et al (2008) Autoimmune polyendocrine syndrome type 1 and NALP5, a parathyroid autoantigen. N Engl J Med 358:1018-1028

62. Del Pilar M, Mackenzie R, Burne P et al (2017) Assessment of autoantibodies to interferon-omega in patients with autoimmune polyendocrine syndrome type 1: using a new immunoprecipitation assay. Clin Chem Lab Med 55:1003-1012

63. Lista Regioni Italiane. Popolazione residente, superficie, percentuali, densità per Kmq, elenco e numero comuni e province. http:// www.comuni-italiani.it/regionip.html

64. Vercelli M, Lillini R, Quaglia A, Micale RT, La Maestra S, De Flora S (2014) Age-related mortality trends in Italy from 1901 to 2008. PLoS One 9:e114027. https://doi.org/10.1371/journal.pone. 0114027

65. Bruserud Ø, Costea DE, Laakso S et al (2018) Oral tongue malignancies in autoimmune polyendocrine syndrome type 1 . Front Endocrinol 9:1-6

66. Gazitt T, Loughran Jr TP (2017) Chronic neutropenia in LGL leukemia and rheumatoid arthritis. Hematol Am Soc Hematol Educ Program 2017:181-186

67. Bockorny B, Dasanu CA (2012) Autoimmune manifestations in large granular lymphocyte leukemia. Clin Lym Myel Leuk 12:400-405

68. Dhodapkar MV, Lust JA, Phyliky RL (1994) T-cell large granular lymphocytic leukemia and pure red cell aplasia in a patient with type I autoimmune polyendocrinopathy: response to immunosuppressive therapy. Mayo Clin Proc 69(11):1085-1088

69. Hervier B, Rimbert M, Maisonneuve H, Hamidou MA (2010) Large granular lymphocyte leukemia with pure red cell aplasia associated with autoimmune polyendocrinopathy-candidiasisectodermal dystrophy: an unfortuitous association? Int J Immunopathol Pharmacol 23:947-949

70. Bensing S, Brandt L, Tabaroj F et al (2008) Increased death risk and altered cancer incidence pattern in patients with isolated or combined autoimmune primary adrenocortical insufficiency. Clin Endocrinol (Oxf) 69:697-704

71. Erichsen MM, Løvås K, Fougner KJ et al (2009) Normal overall mortality rate in Addison's disease, but young patients are at risk of premature death. Eur J Endocrinol 160:233-237

72. Borchers J, Pukkala E, Makitie O, Laakso S (2020) Patients with APECED have increased early mortality due to endocrine causes, malignancies and infections. J Clin Endocrinol Metab 105:1-7

73. Naletto L, Frigo AC, Ceccato F et al (2019) The natural history of autoimmune Addison's disease from the detection of autoantibodies to development of the disease: a long-term follow-up study on 143 patients. Eur J Endocrinol 180:223-234

74. Betterle C, Presotto F, Furmaniak J (2019) Epidemiology, pathogenesis, and diagnosis of Addison's disease in adults. J Endocrinol Invest 42:1407-1433

75. Hoek A, Schoemaker J, Drexhage HA (1997) Premature ovarian failure and ovarian autoimmunity. Endo Rev 18:107-134

76. Bakalov VK, Anasti JN, Calis KA et al (2005) Autoimmune oophoritis as a mechanism of follicular dysfunction in women with 46, XX spontaneous premature ovarian failure. Fertil Steril 84:958-965 
77. Reato G, Morlin L, Chen S et al (2011) Premature ovarian failure in patients with autoimmune Addison's disease: clinical, genetic, and immunological evaluation. J Clin Endocrinol Metab 96:E1255-1261

78. Dalla Costa M, Bonanni G, Masiero S et al (2014) Gonadal function in males with autoimmune Addison's disease and autoantibodies to steroidogenic enzymes. Clin Exp Immunol 176:373-379

79. Scarpa R, Alaggio R, Norberto L et al (2013) Tryptophan hydroxylase autoantibodies as markers of a distinct autoimmune gastrointestinal component of autoimmune polyendocrine syndrome type 1. J Clin Endocrinol Metab 98:704-712

80. Kluger N, Jokinen M, Lintulahti A, Krohn K, Ranki A (2015) Gastrointestinal immunity against tryptophan hydroxylase-1, aromatic L-amino-acid decarboxylase, AIE-75, villin and Paneth cells in APECED. Clin Immunol 158:212-220

81. Betterle C, Spadaccino AC, Presotto F et al (2002) The number of markers of pancreatic autoimmunity is proportional to the risk for type 1 diabetes mellitus in Italian and English patients with organspecific autoimmune diseases. Ann N Y Acad Sci 958:276-280

82. Ziegler AG, Kick K, Bonifacio E et al (2020) Fr1da study group. yield of a public health screening of children for islet autoantibodies in Bavaria, Germany. JAMA 323:339-351
83. Fierabracci A (2016) Type 1 diabetes in autoimmune polyendocrinopathy-candidiasis-ectodermal dystrophy syndrome (APECED): a "rare" manifestation in a "rare" disease. Int J Mol Sci 17:1106

84. Ilmarinen T, Eskelin P, Halonen $M$ et al (2005) Functional analysis of SAND mutations in AIRE supports dominant inheritance of the G228W mutation. Hum Mutat 26:322-331

85. Oftedal BE, Hellesen A, Erichsen MM et al (2015) Dominant mutations in the autoimmune regulator AIRE are associated with common organ-specific autoimmune diseases. Immunity 42:1185-1196

86. Passos GA, Speck-Hernandez CA, Assis AF, Mendes-da-Cruz DA (2017) Update on Aire and thymic negative selection. Immunology $153: 10-20$

87. Capalbo D, Fusco A, Aloj G et al (2012) High intrafamilial variability in autoimmune polyendocrinopathy-candidiasis-ectodermal-dystrophy: a case study. J Endocrinol Invest 35:77-81

Publisher's Note Springer Nature remains neutral with regard to jurisdictional claims in published maps and institutional affiliations.

\section{Authors and Affiliations}

S. Garelli ${ }^{1,2} \cdot$ M. Dalla Costa ${ }^{1,3} \cdot$ C. Sabbadin ${ }^{1} \cdot$ S. Barollo ${ }^{1} \cdot$ B. Rubin ${ }^{1} \cdot$ R. Scarpa ${ }^{1} \cdot$ S. Masiero ${ }^{1} \cdot$ A. Fierabracci ${ }^{4}$. C. Bizzarri ${ }^{5}$ - A. Crinò ${ }^{5} \cdot$ M. Cappa ${ }^{5} \cdot$ M. Valenzise ${ }^{6}$. A. Meloni ${ }^{7}$ - A. M. De Bellis ${ }^{8}$. C. Giordano ${ }^{9} \cdot$ F. Presotto ${ }^{2}$. R. Perniola ${ }^{10}$ - D. Capalbo ${ }^{11}$ - M. C. Salerno ${ }^{12}$ - A. Stigliano ${ }^{13}$ - G. Radetti ${ }^{14}$ - V. Camozzi ${ }^{1}$ - N. A. Greggio ${ }^{15} \cdot$ F. Bogazzi $^{16}$. I. Chiodini ${ }^{17}$. U. Pagotto ${ }^{18}$. S. K. Black ${ }^{19}$. S. Chen ${ }^{19}$. B. Rees Smith ${ }^{19}$. J. Furmaniak ${ }^{19}$. G. Weber ${ }^{20} \cdot$ F. Pigliaru $^{21}$. L. De Sanctis ${ }^{22} \cdot$ C. Scaroni ${ }^{1} \cdot$ C. Betterle ${ }^{1}$

1 Endocrine Unit, Department of Medicine (DIMED), University of Padua, Via Ospedale Civile 105, 35128 Padua, Italy

2 Unit of Internal Medicine, Ospedale dell'Angelo, Mestre-Venice, Italy

3 Unit of Internal Medicine, Ospedale di Feltre, Belluno, Italy

4 Infectivology and Clinical Trials Research Department, Bambino Gesù Children's Hospital, IRCCS, Rome, Italy

5 Endocrine Unit, Bambino Gesù Children's Hospital, IRCCS, Rome, Italy

6 Unit of Pediatrics, Department of Adulthood and Childhood Human Pathology, University of Messina, Messina, Italy

7 Ospedale Microcitemico and Dipartimento di Scienze Biomediche e Biotecnologiche, University of Cagliari, Cagliari, Italy

8 Unit of Endocrinology and Metabolic Diseases, Department of Advanced Medical and Surgical Sciences, University of Campania “Luigi Vanvitelli”, Naples, Italy

9 Endocrine Unit, Department of Biomedical Internal and Specialist Medicine (DIBIMIS), Palermo University, Palermo, Italy

10 Department of Pediatrics, Regional Hospital Vito Fazzi, Lecce, Italy

11 Department of Mother and Child, University Federico II, Naples, Italy
12 Pediatric Section, Department of Translational Medical Sciences, University Federico II, Naples, Italy

13 Endocrinology, Department of Clinical and Molecular Medicine, Sant'Andrea Hospital, Sapienza University of Rome, Rome, Italy

14 Marienklinik, General Hospital, Bolzano, Italy

15 EU-Endo-ERN Advisory Board Member, National Coordinator Endo-ERN Pediatric (SIEDP), Padua, Italy

16 Department of Clinical and Experimental Medicine, University of Pisa, Pisa, Italy

17 Unit of Bone Metabolism Diseases and Diabetes, Istituto Auxologico Italiano, Department of Medical Biotechnology and Translational Medicine, University of Milan, Milan, Italy

18 Unit of Endocrinology and Prevention and Care of Diabetes, Department of Medical and Surgical Sciences (DIMEC), University of Bologna, Bologna, Italy

19 FIRS Laboratories RSR Ltd, Cardiff, UK

20 Unit of Pediatrics, Vita-Salute San Raffaele University, IRCSS San Raffaele Scientific Institute, Milan, Italy

21 Endocrine Unit, Azienda Ospedaliera-Universitaria of Cagliari, Cagliari, Italy

22 Pediatric Endocrinology, Department of Public Health and Pediatric Sciences, Regina Margherita Children's Hospital, University of Turin, Turin, Italy 